\title{
Second Messengers, Trafficking-Related Proteins, and Amino Acid Residues that Contribute to the Functional Regulation of the Rat Brain GABA Transporter GAT1
}

\author{
Michael W. Quick, ${ }^{1}$ Janis L. Corey, ${ }^{2}$ Norman Davidson, ${ }^{2}$ and Henry A. Lester ${ }^{2}$ \\ ${ }^{1}$ Department of Neurobiology, University of Alabama at Birmingham, Birmingham, Alabama 35294-0021, and 2Division of \\ Biology, California Institute of Technology, Pasadena, California 91125
}

Recent evidence indicates that several members of the $\mathrm{Na}^{+}$coupled transporter family are regulated, and this regulation in part occurs by redistribution of transporters between intracellular locations and the plasma membrane. We elucidate components of this process for both wild-type and mutant GABA transporters (GAT1) expressed in Xenopus oocytes using a combination of uptake assays, immunoblots, and electrophysiological measurements of membrane capacitance, transportassociated currents, and GAT1-specific charge movements. At low GAT1 expression levels, activators of protein kinase C (PKC) induce redistribution of GAT1 from intracellular vesicles to the plasma membrane; at higher GAT1 expression levels, activators of PKC fail to induce this redistribution. However, coinjection of total rat brain mRNA with GAT1 permits PKCmediated modulation at high transporter expression levels. This effect of brain mRNA on modulation is mimicked by coinjection of syntaxin 1a mRNA and is eliminated by injecting synapto- physin or syntaxin antisense oligonucleotides. Additionally, botulinum toxins, which inactivate proteins involved in vesicle release and recycling, reduce basal GAT1 expression and prevent PKC-induced translocation. Mutant GAT1 proteins, in which most or all of a leucine heptad repeat sequence was removed, display altered basal distribution and lack susceptibility to modulation by PKC, delineating one region of GAT1 necessary for its targeting. Thus, functional regulation of GAT1 in oocytes occurs via components common to transporters and to trafficking in both neural and non-neural cells, and suggests a relationship between factors that control neurotransmitter secretion and the components necessary for neurotransmitter uptake.

Key words: neurotransmitter transporters; intracellular trafficking; leucine heptad repeats; synaptic vesicle proteins; second messengers; protein regulation
Plasma membrane neurotransmitter transporters use an electrochemical gradient for $\mathrm{Na}^{+}$to move neurotransmitters across membranes. Their location and capacity for removing neurotransmitters suggest that transporters play an important role in synaptic physiology (Iversen, 1975). Detailed analyses indicate that synaptic events could be influenced either by (1) the speed of ratelimiting steps in the transport cycle; or (2) the density of transporter molecules at the synapse (Mager et al., 1993; Sarantis et al., 1993; Lester et al., 1994, 1996). Transporters are subject to regulatory mechanisms that affect each of these parameters, suggesting that modulation of function may be important in transporter function. For example, glutamate transport rates are modulated by direct phosphorylation of the protein (Sardet et al., 1990; Casado et al., 1993). Modulation by changes in transporter density occurs for the facilitated glucose transporter: insulin increases glucose transport by recruiting transporters from cytoplasmic vesicles to the plasma membrane (Cushman and Wardzala, 1980; Suzuki and Kono, 1980).

We have demonstrated previously modulation of transport activity

Received Aug. 9, 1996; revised Jan. 23, 1997; accepted Feb. 13, 1997.

This research was supported by United States Public Health Service Grants NS-11756 (H.A.L.), DA-09121 (H.A.L.), DA-10509 (M.W.Q.), National Research Service Award fellowships (M.W.Q. and J.L.C.), and the W. M. Keck Foundation 931360 (M.W.Q)

Correspondence should be addressed to Dr. Michael W. Quick, Department of Neurobiology, CIRC 446, 1719 Sixth Avenue South, Birmingham, AL 35294-0021.

Dr. Corey's present address: SIBIA, 505 Coast Boulevard South, La Jolla, CA 92037-4641.

Copyright (C) 1997 Society for Neuroscience $\quad 0270-6474 / 97 / 172967-13 \$ 05.00 / 0$ for the rat brain GABA transporter GAT1 expressed in Xenopus oocytes (Corey et al., 1994). Our conclusion that modulation occurs via redistribution of the transporter between the cytoplasm and the plasma membrane, similar to that shown for the facilitated glucose transporter, is based on several observations. (1) Activation of protein kinase $\mathrm{C}(\mathrm{PKC})$ increases GABA transport, and this increase correlates with an increase in the maximum velocity of transport $\left(V_{\max }\right)$. (2) Modulation does not affect the $K_{\mathrm{m}}$ of the transporter. (3) Subcellular fractionation of oocyte membranes reveals that upon PKC stimulation, most transporters are associated with the plasma membrane fraction; inhibition of PKC results in most transporters being located intracellularly. More recently, the $\mathrm{Na}^{+}$-dependent glucose transporter in epithelial cells (Delézay et al., 1995) and the human serotonin transporter expressed in HEK-293 cells (Qian et al., 1997) have been shown to be modulated by PKC-induced alterations in cell surface transporter expression. The fact that modulation by membrane trafficking, first identified for the facilitated glucose transporter present in adipocytes and muscle cells (Cushman and Wardzala, 1980; Suzuki and Kono, 1980), occurs for $\mathrm{Na}^{+}$coupled transporters expressed in epithelial cells and oocytes suggests that there are common mechanisms present in different cell types despite a lack of detailed amino acid similarity among these transporters. We now extend our studies on the mechanisms of GAT1 modulation based on factors shown to regulate trafficking and expression of transporters in both neural and non-neural cells.

In this report, we use Xenopus oocytes to permit high-level expression of wild-type and mutant transporters, to identify trafficking proteins affecting GAT1 expression, and to allow for detailed phys- 
iological measurements of transporter modulation. We find (1) that modulation of GABA transport is affected by coexpression of rat brain mRNA; (2) that this effect requires proteins associated with intracellular trafficking and secretion; (3) that the translocation process underlying GAT1 modulation is affected by toxins known to inhibit proteins required for neurotransmitter exocytosis; and (4) that elimination of a leucine heptad repeat in the primary amino acid sequence of GAT1 changes the basal distribution of GAT1 and eliminates modulation by PKC.

\section{MATERIALS AND METHODS}

Materials. $\left[{ }^{3} \mathrm{H}\right] \mathrm{GABA}$ was purchased from DuPont New England $\mathrm{Nu}-$ clear. Phorbol 12-myristate 13-acetate (PMA), bisindolylmaleimide, and botulinum toxins were obtained from Calbiochem. Horseradish peroxidase (HRP)-conjugated donkey anti-rabbit Ig was purchased from Amersham. All other reagents were obtained from Sigma. PMA and bisindolylmaleimide were dissolved in ethanol and dimethyl sulfoxide, respectively, and then diluted at least 100 -fold in ND96 $(96 \mathrm{~mm} \mathrm{NaCl}, 2$ $\mathrm{mm} \mathrm{KCl}, 1.8 \mathrm{~mm} \mathrm{CaCl}_{2}, 1 \mathrm{~mm} \mathrm{MgCl}_{2}$, and $5 \mathrm{~mm}$ HEPES, $\mathrm{pH}$ 7.4) before oocyte injection. The botulinum toxins were obtained in $50 \mathrm{~mm}$ sodium acetate and $200 \mathrm{~mm} \mathrm{NaCl}, \mathrm{pH} 6.0$, at a concentration of $1 \mathrm{mg} / \mathrm{ml}$ and, unless otherwise noted, diluted 20-fold in ND96 before injection. Human syntaxin 1a (in pcDNAIII) was provided by Dr. K. Kirk (University of Alabama at Birmingham), poly $\left(\mathrm{A}^{+}\right)$rat liver RNA was provided by Dr. P. Chen (University of Alabama at Birmingham), and SKF89976A was a generous gift of W. Bondinell (SmithKline Beecham).

Antisera. The polyclonal rabbit antiserum 342J (a gift from N. Brecha, University of California, Los Angeles, CA) was generated against a peptide corresponding to the carboxyl terminus (amino acids 588-599) of the rat brain GABA transporter GAT1 (Guastella et al., 1990).

Mutagenesis of GAT1 and cRNA synthesis. Leucine-to-alanine mutations (L83A, L90A, L97A, and L104A) were performed using the Clontech Transformer Site-Directed Mutagenesis kit and verified by sequencing. RNA encoding GAT1 was synthesized using the Ambion Megascript in vitro Transcription kit. The DNA template for the transcription reaction was generated by PCR as described previously (Corey et al., 1994). Rat brain RNA was extracted from fresh brains of 21-d-old rats using a modified LiCl-urea procedure (Dierks et al., 1981). Poly $\left(\mathrm{A}^{+}\right)$RNA was prepared by oligo-dT cellulose (type III, Collaborative Research) chromatography as described (Leonard et al., 1987).

Preparation of sense and antisense oligonucleotides. Synaptophysin oligonucleotides were synthesized by the Caltech Oligonucleotide Synthesis facility; syntaxin 1a oligonucleotides were synthesized by Cruachem. Oligonucleotides were 19-mers selected from divergent regions in published sequences. The rat synaptophysin (Sudhof et al., 1987) oligonucleotide was (sense strand, corresponding to bases -1 to 18) CATGGACGTGGTGAATCAG; the rat syntaxin (Bennett et al., 1992) oligonucleotide was (sense strand, corresponding to bases -1 to 18) GATGAAGGATCGGACTCAG. The oligonucleotides were phenolchloroform extracted, recovered by ethanol precipitation, and dissolved in $\mathrm{H}_{2} \mathrm{O}$.

Xenopus oocyte expression and transport assays. These methods are described in detail elsewhere (Quick and Lester, 1994). Briefly, oocytes were defolliculated and maintained at $18^{\circ} \mathrm{C}$ in ND96 supplemented with $2.5 \mathrm{~mm}$ sodium pyruvate, $50 \mu \mathrm{g} / \mathrm{ml}$ gentamycin, and $5 \%$ horse serum. GAT1 cRNA (0.5-5 ng) was injected into each oocyte; $50 \mathrm{ng}$ of poly $\left(\mathrm{A}^{+}\right)$selected rat brain RNA was used for the coinjection experiments. Assays were performed $2-5$ d postinjection. To standardize the drug delivery procedure, all compounds were introduced into the oocyte by microinjection as described (Corey et al., 1994). Unless otherwise noted, $25 \mathrm{nl}$ of the following compounds were microinjected into GAT1-expressing oocytes (approximate final concentrations): $400 \mathrm{nM}$ PMA, $100 \mathrm{~nm}$ bisindolylmaleimide, $1 \mathrm{ng}$ of botulinum toxin (BoNt)/B and $\mathrm{BoNt} / \mathrm{C}$, and $50 \mathrm{ng}$ of BoNt/A. To measure GABA uptake, oocytes were placed in ND96 to which a final concentration of $260 \mathrm{~nm}\left[{ }^{3} \mathrm{H}\right] \mathrm{GABA}$ was added in timed intervals. The reaction was terminated by removal of the oocyte and multiple washes in ND96. The oocyte was then solubilized in 10\% SDS, and $\left[{ }^{3} \mathrm{H}\right] \mathrm{GABA}$ uptake was determined by liquid scintillation counting. For experiments involving coinjection of rat brain RNA, $20 \mu \mathrm{M}$ bicuculline and $10 \mu \mathrm{M}$ phaclofen were included with the extracellular GABA to block potential responses attributable to GABA receptor stimulation. Values in the text are expressed as the mean \pm SEM.

Electrophysiology. Two-microelectrode voltage-clamp procedures were used (Quick and Lester, 1994). Whole-cell currents were measured using either a Dagan 8500 or a GeneClamp 500 (Axon Instruments) amplifier. Electrodes were filled with $3 \mathrm{M} \mathrm{KCl}$ and had a resistance of 1-2 $\mathrm{M} \Omega$. Current was measured on-line by oscilloscope and chart recorder. Data acquisition and analysis used the pClamp program suite (Axon Instruments). Measurements of GAT1 charge movements were as described (Mager et al., 1993). Briefly, the membrane potential was held at $-40 \mathrm{mV}$ and jumped to $-100 \mathrm{mV}$ for $1 \mathrm{sec}$. Each oocyte was tested in the presence and absence of SKF89976A to isolate (by subtraction) the charge movements associated with the presence of GAT1 in the plasma membrane. The transient currents generated by these jumps were integrated to yield the amount of charge movement in and out of the oocyte's membrane field. Surface transporter number was calculated using the equation:

$$
N=\frac{Q_{\max }}{q z \delta}
$$

where $N$ is the number of transporters per oocyte, $Q_{\max }$ is the total charge movement, $q$ is the elementary charge, and $z \delta$ is the sum total of the distance that all charges move within the membrane field. We assumed that the value of $z \delta$ for the GAT1 transporter is 1.0 (Mager et al., 1993).

Membrane fractionation, electrophoresis, and immunoblot analysis. These procedures are detailed by Corey et al. (1994). Briefly, oocytes expressing GAT1 were injected with the modulatory compound(s) (25 oocytes per condition were injected within $10 \mathrm{~min}$ ) and incubated for an additional 20-50 min before homogenization. Oocytes were then homogenized, centrifuged, and layered on a discontinuous sucrose gradient. After centrifugation, $1 \mathrm{ml}$ fractions were collected from the bottom of the gradient. Previous analyses indicated that GAT1 was found only in fractions enriched for plasma membrane (fractions 5 and 6) and transGolgi/cytoplasmic vesicles (fractions 9 and 10) (Corey et al., 1994). Therefore, fractions 5 and 6 were pooled and fractions 9 and 10 were pooled within each condition. The pooled samples were diluted sixfold with $0.15 \mathrm{M}$ sucrose in TE buffer (10 mM Tris, $1 \mathrm{~mm}$ EDTA). The remaining samples were diluted 12 -fold with the same buffer, pelleted by centrifugation, resuspended in $20 \mu \mathrm{l}$ sample buffer (Laemmli, 1970), and stored at $-80^{\circ} \mathrm{C}$. Proteins in the microsomal membrane fractions were separated by SDS-PAGE on $10 \%$ gels and electrophoretically transferred to polyvinylidene difluoride membrane (Pierce). The immunoblotting procedure included a $60 \mathrm{~min}$ incubation with the polyclonal antibody against GAT1 (342J) diluted 1:200 and a 30 min incubation with HRPconjugated donkey anti-rabbit Ig antibody diluted 1:1000. A $67 \mathrm{kDa}$ band, shown to be GAT1 (Corey et al., 1994), was detected by visualization using electrochemiluminescence reagents (Amersham). Only the pooled fractions enriched for the plasma membrane and cytoplasmic vesicles are shown in the figures. The other fractions were run separately, and no GAT1 immunoreactivity was detected in any of the samples (data not shown).

\section{RESULTS}

\section{Coinjection of rat brain mRNA permits PMA-induced modulation of GAT1 at high expression levels}

Previous data examining GAT1 modulation showed that as transporter expression increased, PKC induced a smaller fractional increase in transport, even though PKC still induced translocation of GAT1 from the intracellular stores to the plasma membrane fraction (Corey et al., 1994). This suggested that some component of the oocyte machinery necessary for functional surface transporter expression was being saturated. We tested this hypothesis in experiments using various combinations of GAT1 cRNA injections, rat brain poly $\left(\mathrm{A}^{+}\right)$-selected mRNA injections $1-5 \mathrm{~d}$ before uptake measurements, and drug injections to manipulate $\mathrm{PKC}$ 10-15 min before the uptake assay. These results are shown in Figure 1. Figure $1 A$ (top) shows the effect of PKC manipulations on $\left[{ }^{3} \mathrm{H}\right] \mathrm{GABA}$ uptake for a single batch of oocytes (examined 24 hr after RNA injection) expressing comparatively low levels of transporter (as determined by basal $\left[{ }^{3} \mathrm{H}\right] \mathrm{GABA}$ uptake activity), although transport was still 20 -fold higher than for oocytes not injected with GAT1 cRNA. In this experiment, a saturating concentration of the PKC activator PMA increased uptake $\sim 70 \%$ 
A
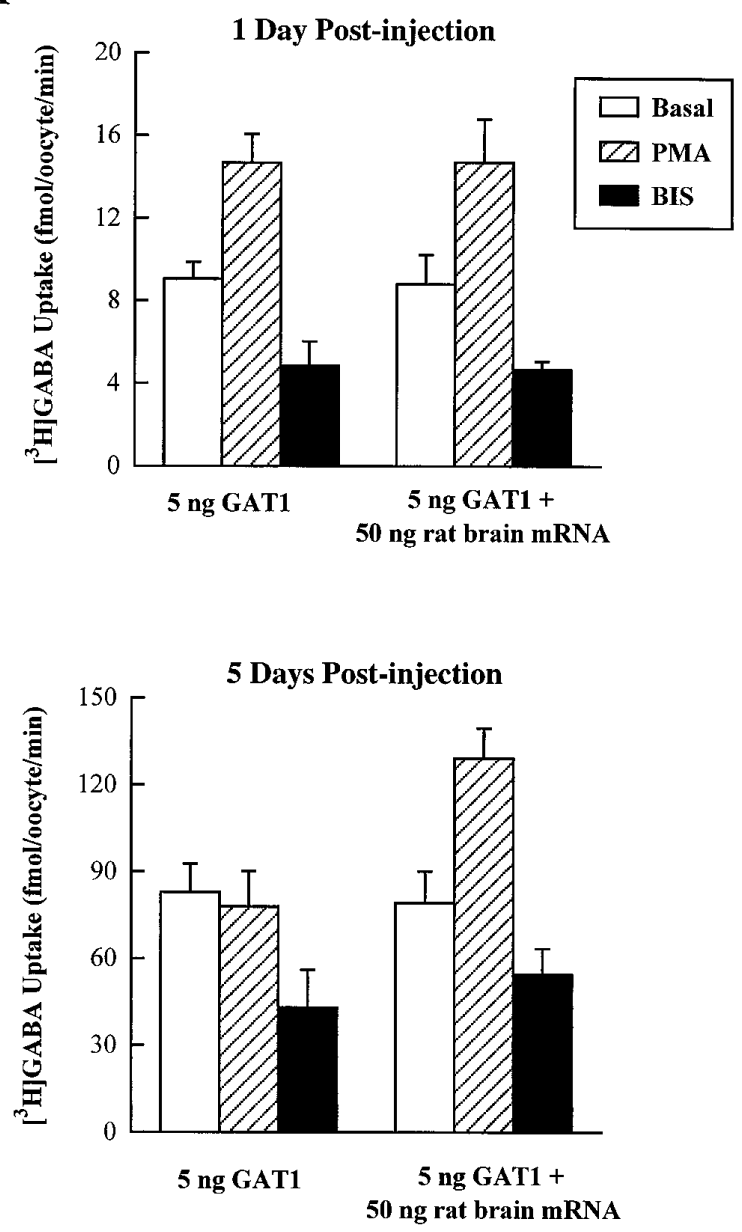

B

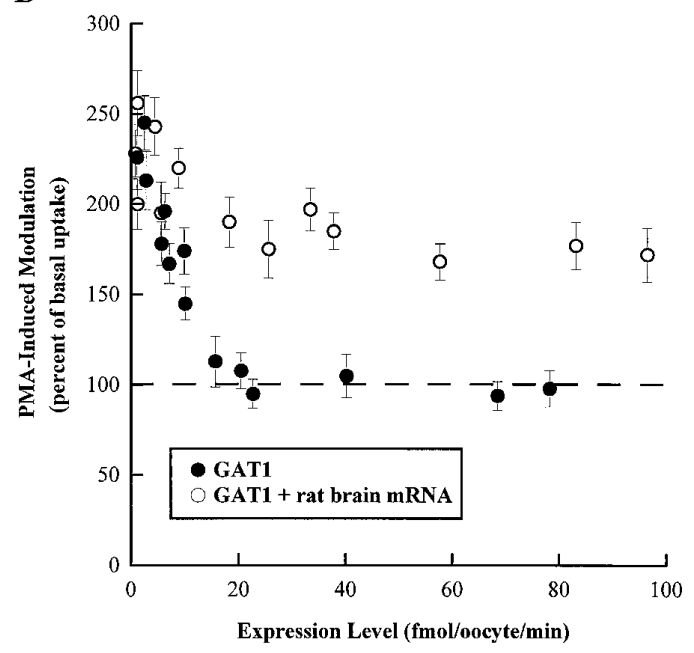

C
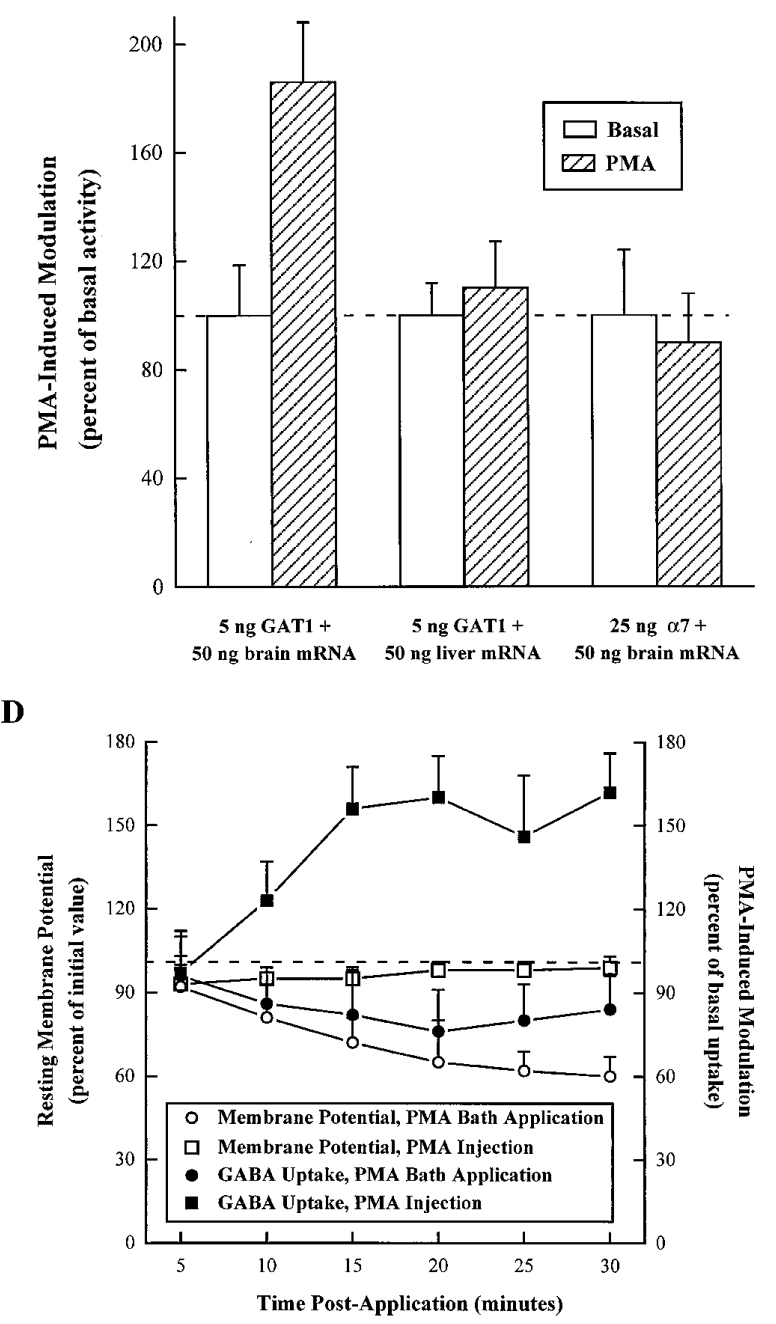

Figure 1. PMA-induced modulation of GAT1 uptake. A, Coinjection of rat brain mRNA allows PMA-induced GAT1 modulation at higher expression levels. Oocytes were injected with $5 \mathrm{ng}$ of GAT1 cRNA alone or in combination with $50 \mathrm{ng}$ of rat brain mRNA, then assayed by $\left[{ }^{3} \mathrm{H}\right] \mathrm{GABA}$ uptake. The assay time was $15 \mathrm{~min}$. Data represent an experiment (5-7 oocytes per condition, mean \pm SEM) for oocytes from a single batch, examined either at $1 \mathrm{~d}$ (low expression; top) or at $5 \mathrm{~d}$ (high expression; bottom) after RNA injection. Before the assay, oocytes were injected with $25 \mathrm{nl}$ of a vehicle solution (Basal, open bars) or a solution containing $400 \mathrm{nM}$ PMA (15 min before assay, hatched bars) or $100 \mathrm{~nm}$ bisindolylmaleimide (BIS;10 min before assay, filled bars). Note that the top and bottom panels have different vertical scales. $B$, Summary of data for the effect of rat brain mRNA coinjection. Expression level is quantified as the amount of $\left[{ }^{3} \mathrm{H}\right] \mathrm{GABA}$ uptake in GAT1 RNA-injected oocytes ( filled circles) or GAT1 and rat brain RNA-injected oocytes (open circles) injected with vehicle solution 15 min before assay (abscissa). The change in uptake induced by 400 nM PMA (ordinate) is plotted as a percentage of vehicle-only injected oocytes. Each data point represents the mean \pm SEM for three to seven oocytes. Expression levels were varied by injecting different amounts of GAT1 cRNA and by performing the assay at different translation times after RNA injection. $C$, PMA modulation shows specificity for GAT1 and rat brain mRNA. Oocytes from the same frog were injected with $5 \mathrm{ng}$ of GAT1 cRNA in combination with either $50 \mathrm{ng}$ of rat brain mRNA or $50 \mathrm{ng}$ of rat liver mRNA; or, oocytes were injected with $25 \mathrm{ng}$ of cRNA encoding the rat homomeric nicotinic acetylcholine receptor $\alpha 7$ in combination with $50 \mathrm{ng}$ of rat brain cRNA. For the GAT1 cRNA-injected oocytes, GABA transport was assessed as described in $A$. For oocytes expressing $\alpha 7$, peak currents induced by perfusion of $200 \mu \mathrm{M}$ nicotine were measured using a two-electrode voltage clamp. The holding potential was $-70 \mathrm{mV}$. The change in function induced by 400 nM PMA (hatched bars) is plotted as a percentage of vehicle-only treated oocytes (open bars). Each data point represents the mean \pm SEM for seven oocytes. $D$, Differential effects of PMA administration on GAT1 uptake. Oocytes were injected with 5 ng of GAT1 cRNA and assayed (5 oocytes per condition) for $\left[{ }^{3} \mathrm{H}\right] \mathrm{GABA}$ uptake after bath application ( filled circles) or injection ( filled squares) with $400 \mathrm{nM}$ PMA. The change in uptake (right ordinate) is plotted as a percentage of vehicle-only treated oocytes. The resting membrane potential for subsets (5 each) of PMA-incubated (open circles) and PMA-injected (open squares) oocytes was monitored electrophysiologically. The results are plotted as a percentage of their resting membrane potential before PMA application (left ordinate). 
above the level for GAT1-expressing oocytes injected with water rather than with PMA. The PKC inhibitor bisindolylmaleimide blocked basal activity by $\sim 50 \%$. These data reproduce our earlier observations (Corey et al., 1994). Figure $1 A$ also shows that coinjection of $50 \mathrm{ng}$ of rat brain mRNA with the GAT1 cRNA did not change the modulation observed at low expression levels. The quality of the rat brain mRNA was verified by both $\left[{ }^{3} \mathrm{H}\right] \mathrm{GABA}$ (twofold above background) and $\left[{ }^{3} \mathrm{H}\right]$ glutamate (sixfold over background) uptake assays in oocytes injected with the rat brain mRNA alone (data not shown).

The bottom panel of Figure $1 A$ summarizes a comparable experiment on oocytes from the same batch at comparatively higher transporter expression levels ( $5 \mathrm{~d}$ after RNA injection). For oocytes injected with only GAT1 cRNA, PMA did not induce an increase in GABA uptake. However, the addition of rat brain mRNA permitted an increase in $\left[{ }^{3} \mathrm{H}\right] \mathrm{GABA}$ transport at high expression levels; this fractional increase $(68 \%$ higher than basal levels) was comparable to the effects seen with GAT1 alone at low expression levels. It should be noted that at high GAT1 expression levels, the amount of GABA transport resulting from the injection of rat brain mRNA is only $\sim 1 \%$ of that resulting from GAT1 cRNA-mediated uptake, and therefore cannot account for the increase in PMA-induced transporter function.

Figure $1 B$ compares PMA-induced functional modulation between oocytes injected with GAT1 cRNA alone and oocytes injected with both GAT1 cRNA and rat brain mRNA. These data represent experiments performed using oocytes from a number of batches. Rat brain mRNA allows modulation at high expression levels whether obtained by increasing the amount of GAT1 cRNA injected or by increasing the postinjection translation time before assay.

Two experiments were performed to assess the specificity of PMA-induced modulation of GAT1 function after coexpression of rat brain mRNA. These results are shown in Figure $1 C$. In oocytes expressing basal transport levels of approximately 100 fmol/oocyte/min (compare with the bottom of Fig. $1 A$ ), the PMAinduced increase in GABA transport occurs in oocytes expressing GAT1 and rat brain mRNA, but not in oocytes expressing GAT1 and rat liver mRNA. These data suggest that some component in the brain mRNA, rather than a nonspecific effect of RNA loading, is responsible for the increases in GABA transport. To test whether this effect is specific to the transporter, we coexpressed rat brain mRNA with another brain membrane protein, the ligand-gated neuronal nicotinic receptor $\alpha 7$. PMA failed to induce a change in nicotine-induced $\alpha 7$-mediated currents as assessed by two-electrode voltage clamp (mean inward currents for oocytes in the basal state at $-70 \mathrm{mV}$ were $235 \mathrm{nA}$ ).

In addition to the translocation of GAT1 by PMA observed in our studies, independent investigations have shown that, under certain conditions and in different cell types, phorbol esters can exert other effects on GABA transporter function, including: (1) increasing the $K_{\mathrm{m}}$ for GABA in oocytes twofold (Osawa et al., 1994); and (2) decreasing $V_{\max } 50 \%$ (at GABA concentrations $>1$ $\mu \mathrm{M}$ ) in 293 cells (Sato et al., 1995). To further understand the mechanisms underlying these multiple effects of phorbol ester treatment and to minimize their impact on the present studies, we examined changes in $\left[{ }^{3} \mathrm{H}\right] \mathrm{GABA}$ uptake and resting membrane potential after different PMA applications. These results are shown in Figure $1 D$. In agreement with other studies, there was a decrease in GABA uptake of $20-30 \%$ in oocytes when PMA was bath-applied. This decrease in uptake correlated with a substantial decrease in the membrane potential of the oocyte (i.e., the membrane potential became less negative) over the same time course. This decrease of the membrane potential was not observed in oocytes injected with PMA, except for a small decrease most likely attributable to the injection process. The delay in both effects, membrane potential and GABA uptake, compared with cytoplasmic injection of PMA, is consistent with the time required for the activator to cross the plasma membrane. These data show that bath application of PMA decreases GABA uptake primarily by decreasing the $\mathrm{Na}^{+}$driving force. In agreement with other studies, we also find that the effect attributable to bath application of PMA is specific; it is reversed with PKC inhibitors (data not shown). Thus, the data suggest that PKC affects transporter function via multiple pathways that occur over different time courses. To date, we have not investigated possible changes in GAT1 subcellular distribution after bath application of PMA, nor have we investigated the effect of bath application of PMA over longer incubation times.

\section{Electrophysiological analysis of GAT1 modulation}

Electrophysiological analysis of GAT1 function is practical only at high expression levels. Because coinjection of rat brain mRNA conferred the ability to modulate GABA transport at high expression levels, it was possible to characterize modulation electrophysiologically. One such set of traces is shown in Figure $2 A$. In this example, the oocyte was voltage-clamped at $-80 \mathrm{mV}$ and superfused with GABA for $10 \mathrm{sec}$. In the basal condition (no PMA), GABA induced a peak inward current of $\sim 90 \mathrm{nA}$. Consistent with the uptake data, the transport-associated currents were approximately twofold larger after PMA injection. The transport-associated currents were completely blocked by the specific GABA transport inhibitor SKF89976A (Yunger et al., 1984), showing that the basal and PMA-enhanced currents were attributable to GABA transporter function. The voltage dependence of basal and PMA-induced currents reveals the pronounced inward rectification characteristic of transporter-associated currents (Fig. 2B).

Previous dose-response analysis of GABA transport in oocytes expressing GAT1 alone suggested that modulation changes the $V_{\text {max }}$ of transport rather than the $\mathrm{EC}_{50}$ (Corey et al., 1994). Because oocytes coinjected with GAT1 and rat brain mRNA showed larger transport-associated currents (and therefore allowed more precise measurements), we extended the earlier dose-response studies and Eadie-Hofstee transformations of basal and PMA-injected oocytes (Fig. $3 A$ ). The PMA modulation was associated with a change in the $V_{\max }$ of transport. This observation agrees with the earlier data and is also consistent with an increase in GAT1 protein in plasma membrane fractions as assessed by Western blot (Fig. $3 A$, inset). No differences in gel mobility were distinguishable in immunoblots between oocytes injected with GAT1 cRNA alone or in combination with rat brain mRNA (data not shown); thus, even when coexpressed with rat brain mRNA, GAT1 is not glycosylated in oocytes (Guastella et al., 1990).

Although the kinetic analysis and immunoblot data discussed above provide strong evidence for modulation attributable to changes in functional surface transporter expression, the ability to modulate the transporter at high expression levels permits direct assessment of this hypothesis based on the fact that each transporter contributes an increment of charge movement in a voltagejump experiment. The rationale for charge movement measurements has been presented in detail previously (Mager et al., 1993, 1996). Briefly, in response to a voltage jump, a transient (100-150 
A

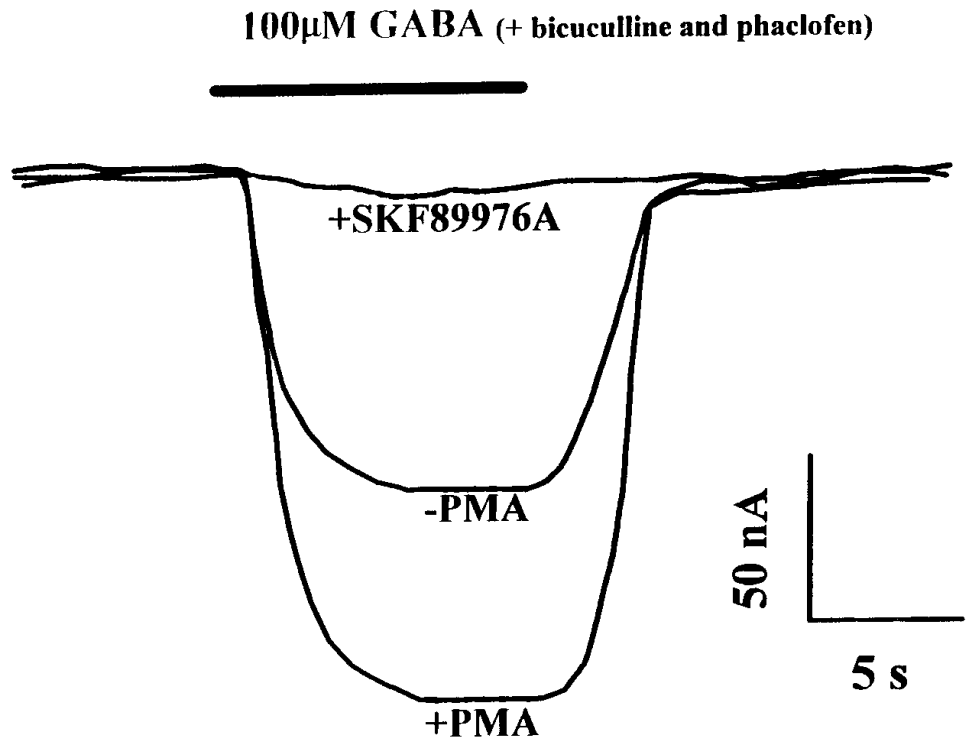

B

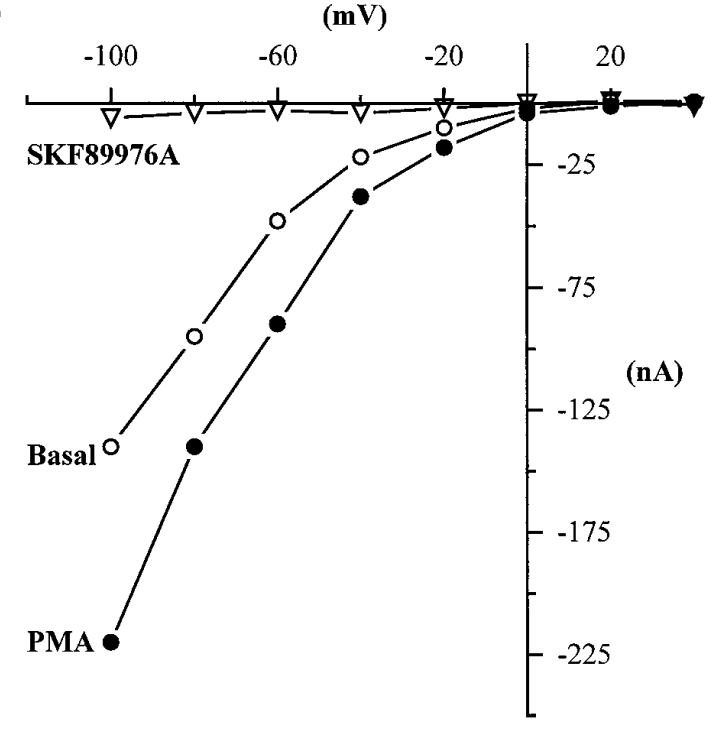

Figure 2. Electrophysiological characterization of PMA-induced GAT1 modulation and block by SKF89976A. $A$, Two-electrode voltage-clamp analysis of GABA-induced currents for a GAT1/rat brain mRNA-injected oocyte. The holding potential was $-80 \mathrm{mV}$. The solid bar above the traces represents the application of $100 \mu \mathrm{M}$ GABA. Bicuculline $(20 \mu \mathrm{M})$ and phaclofen $(10 \mu \mathrm{M})$ were included to block potential responses attributable to GABA receptor stimulation. PMA (400 nM) was injected after measurement of the basal condition; the PMA-induced trace was recorded 20 min later. The response in the presence of $10 \mu \mathrm{M}$ SKF89976A was recorded 5 min later. $B$, Current-voltage relationship for another oocyte recorded as described in $A$ and subjected to voltage ramps from $-100 \mathrm{mV}$ to $+40 \mathrm{mV}$ over $1 \mathrm{sec}$.

msec) current flows in oocytes injected with GAT1, but not in uninjected or water-injected oocytes. The time integral of the currents is a charge movement. In the absence of GABA, this charge movement is equal and opposite for reciprocal jumps; i.e., it is purely capacitive and occurs because ions move into and out of the membrane dielectric while binding to the transporter. Importantly, the charge movements are blocked by the GABA transporter-specific inhibitor SKF89976A. Therefore, the GAT1specific charge movements can be isolated by subtracting current traces measured in the presence and absence of SKF89976A. As described in Materials and Methods, this charge movement difference attributable to transporter expression can be converted to surface transporter number.

Analysis of modulation by charge movement measurements, however, is complicated slightly by a nonspecific reduction in membrane area induced by PMA (Bourinet et al., 1992; Schmalzing et al., 1995). Figure $3 B$ shows that SKF89976A subtraction nonetheless avoids distortion from this effect. In oocytes injected with rat brain mRNA alone, PMA induces a reduction in oocyte membrane capacitance of $\sim 35 \%$. This reduction in capacitance also occurs in uninjected and water-injected oocytes (data not shown). Superfusion of SKF89976A has no measurable effect on the membrane capacitance in rat brain mRNA-injected oocytes, even though it is probably blocking the relatively small amount of GAT1 that is encoded by the rat brain mRNA. The coinjection of GAT1 cRNA with rat brain mRNA results in less reduction in membrane capacitance attributable to PMA injection; i.e., compared with PMA-injected control oocytes, there is an increase in capacitance in GAT1-coexpressing oocytes. This increase in capacitance is completely blocked by superfusion of SKF89976A, suggesting that the difference in capacitance measured before and after SKF89976A application is attributable to the GAT1 charge movements. An alternative method, to avoid the nonspecific capacitance changes attributable to membrane retrieval, relies on the fact that the passive capacitive currents are much faster (time constant of $<5 \mathrm{msec}$, depending on the speed of the voltageclamp circuit) than the GAT1 charge movements (time constants of 50-100 msec) (Mager et al., 1993, 1996). The GAT1 charge movements can therefore be determined by beginning the integration $\sim 5 \mathrm{msec}$ after the voltage jump. This method yields equivalent results to the SKF89976A subtraction method (data not shown).

Thus, charge movements provide a measure of changes in functional transporter number on the cell surface during modulation. Figure $3 C$ shows that these measurements explain the lack of modulation of PMA in oocytes expressing GAT1 alone at high levels, even though PMA does induce translocation of the transporter protein to the plasma membrane fraction (Corey et al., 1994). In oocytes coinjected with GAT1 cRNA and rat brain RNA, PMA induces a time-dependent increase in functional surface transporter number compared with vehicle-injected controls. In contrast, oocytes injected with GAT1 cRNA only, and expressing at high levels, fail to show increases in functional surface transporters in response to PMA. A simple interpretation of these results is that (1) increasing quantities of GAT1 saturate a component necessary for GAT1 expression; and (2) rat brain RNA provides components necessary for functional surface expression of large quantities of GAT1 after translocation to the plasma membrane fraction.

The above conclusions are strengthened by examining the relationship among our three measures of GABA transporter trafficking and function. These data are shown in Figure $3 D$. A single batch of oocytes was injected with GAT1 and rat brain cRNA. These oocytes were then assayed by uptake, charge movement measurements, and immunoblot over 5 consecutive d postinjection. The uptake and charge movement measurements show a nearly superimposable rise, suggesting that the modulation of uptake is indeed attributable to a change in functional transporter 
A

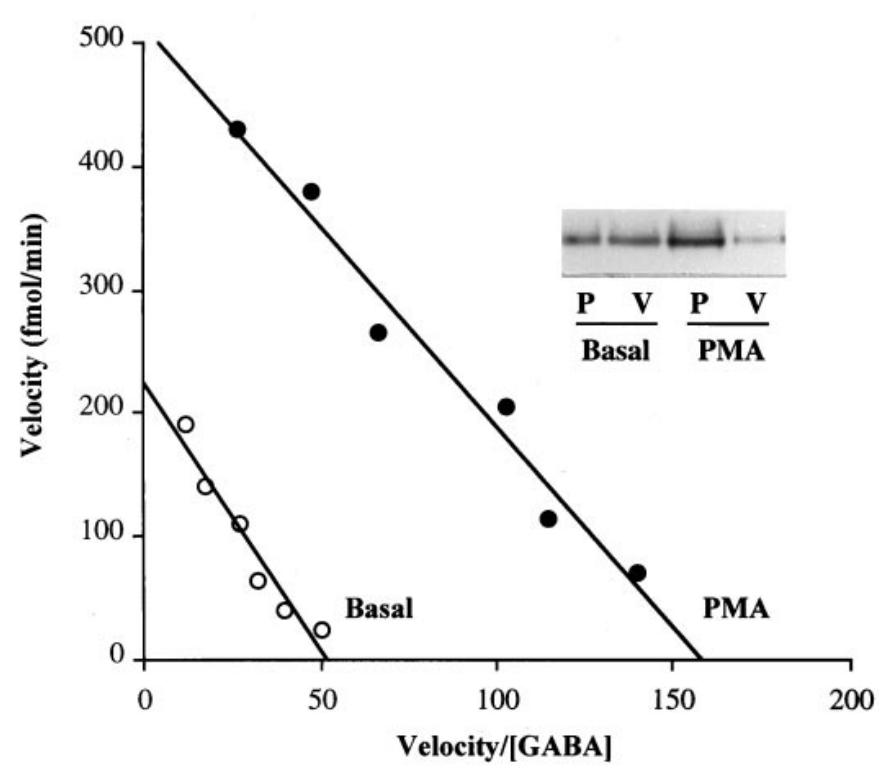

C

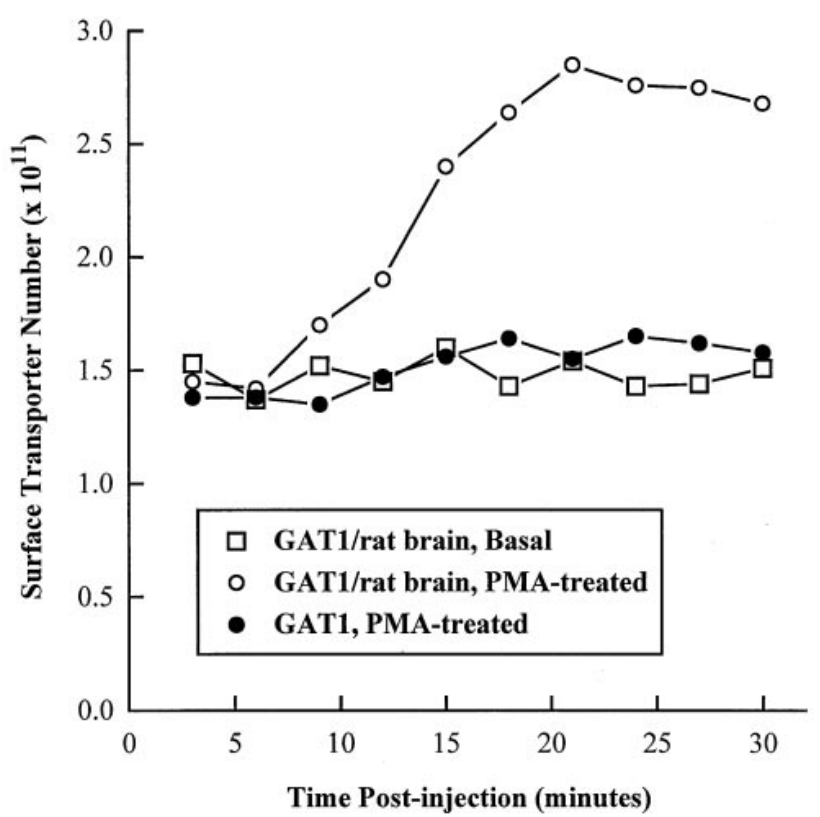

B

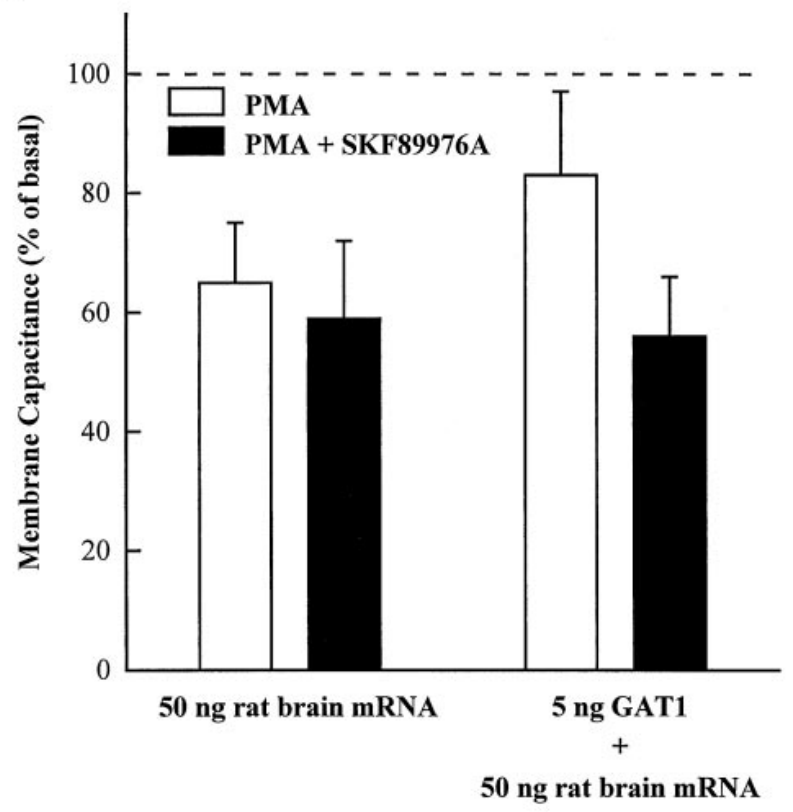

D

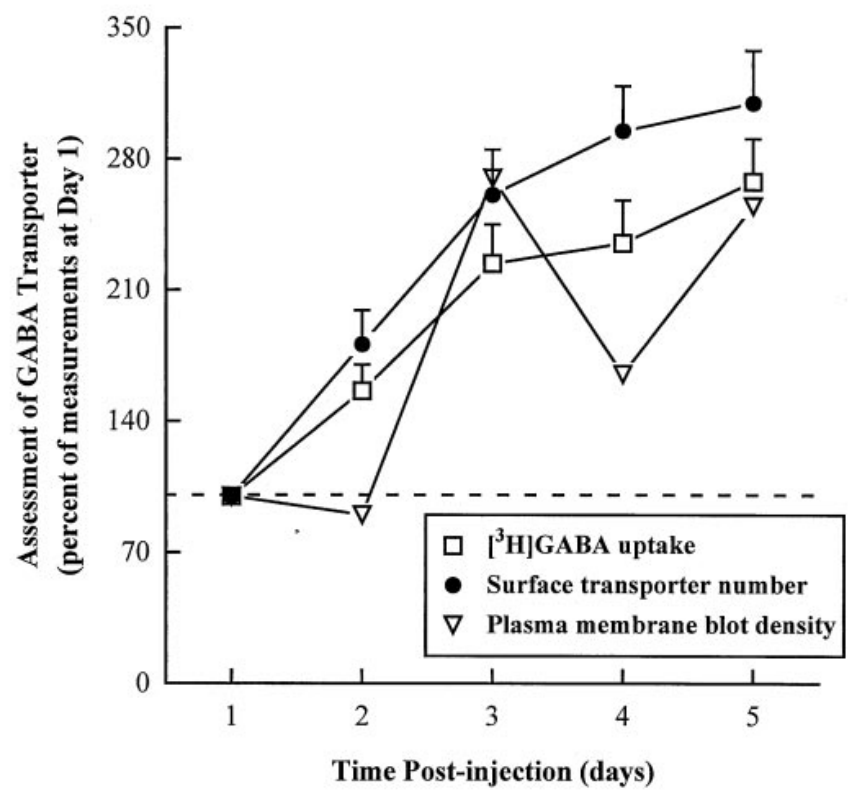

Figure 3. PMA-induced modulation occurs by increasing surface transporter expression. Oocytes were injected with 5 ng of GAT1 cRNA and/or 50 ng of rat brain mRNA and assayed $4 \mathrm{~d}$ postinjection. PMA $(25 \mathrm{nl} ; 400 \mathrm{nM})$ was injected 15 min before assay. $A$, Eadie-Hofstee transformation of dose-response $\left[{ }^{3} \mathrm{H}\right]$ GABA uptake data for basal (open circles) and PMA ( filled circles) conditions (5 oocytes per condition). The assay time was 15 min. GABA concentrations were $0.5,1,2,4,8$, and $16 \mu \mathrm{M}$. The average SEM across all conditions was $16.4 \%$ of mean values. Inset shows PMA-induced translocation of GAT1 as assessed by Western blot. $B$. Changes in cell capacitance associated with PMA injection. Membrane potential was held at -40 $\mathrm{mV}$ and stepped to $-100 \mathrm{mV}$ for $1 \mathrm{sec}$ in the presence ( filled bars) and absence (open bars) of $10 \mu \mathrm{M}$ SKF89976A. Capacitance data are presented as a percentage of the basal capacitance measured before PMA injection. Five oocytes were tested in each of the injection conditions; each oocyte was tested in the absence and presence of SKF89976A. C, PMA-induced (circles) changes in oocyte plasma membrane transporter number as assessed by measurement of charge movements. Calculations are described in Materials and Methods. Oocytes were injected either with 5 ng of GAT1 cRNA alone ( filled symbols) or GAT1 cRNA plus $50 \mathrm{ng}$ of rat brain mRNA (open symbols). Oocytes in the basal condition (squares) were control-injected with $25 \mathrm{nl}$ of water. The data presented are from individual oocytes with comparable initial charge movements and are representative of five oocytes/condition. $D$, Comparison of GABA uptake, surface GABA transporter number, and plasma membrane protein levels. Oocytes from a single frog were injected with $5 \mathrm{ng}$ of GAT1 cRNA and $50 \mathrm{ng}$ of rat brain mRNA and assayed for 5 consecutive d. $\left[{ }^{3} \mathrm{H}\right] \mathrm{GABA}$ uptake (squares) assays were 15 min $(5$ oocytes/data point). Surface transporter number (circles) was calculated from GAT1-specific charge movements as described in Materials and Methods (5 oocytes/data point). Subcellular fractionation was performed on parallel oocyte samples ( 25 oocytes/sample) and analyzed by immunoblot as described in Materials and Methods. GAT1 protein present in plasma membrane (triangles) was measured by densitometry (nominal units). All data are plotted relative to the values obtained on day 1 . 
number. Protein levels of GAT1 also increased over this time period; however, these results were less precise and showed greater variability. Therefore, these data also remain consistent with the possibility that transporter protein levels in the plasma membrane fraction do not precisely parallel functional surface transporter number or transport rates. We suggested previously that there is an additional, inactive state of the transporter in the plasma membrane fraction (Corey et al., 1994).

\section{Role of trafficking-related proteins in modulation of GABA transport}

Two lines of evidence suggested the hypothesis that components involved in vesicle exocytosis and recycling and in protein trafficking may be involved in transporter trafficking and expression, and that these may be the limiting factor in oocytes. First, the trafficking of transporters for intracellular storage, their regulated expression on the plasma membrane, and their modulation of expression by second messengers parallel events that occur during vesicle secretion and protein trafficking (Bennett et al., 1992; Blasi et al., 1993b). Second, these components must be added exogenously to oocytes to reconstitute neurotransmitter secretion (Alder et al., 1992).

To address this possibility, we used an antisense strategy to eliminate PMA-induced modulation at high transporter expression levels in oocytes coinjected with GAT1 and rat brain RNA. The results using antisense oligonucleotides to the trafficking proteins synaptophysin and syntaxin 1a are shown in Figure 4. Sense and antisense oligonucleotides corresponding to divergent sequences of these proteins were synthesized and individually injected into oocytes. Standard $\left[{ }^{3} \mathrm{H}\right] \mathrm{GABA}$ uptake assays in oocytes expressing high amounts of the transporter showed that antisense synaptophysin and antisense syntaxin 1a oligonucleotides eliminated the PMA-induced modulation of GAT1 present in control oocytes injected with sense oligonucleotides (Fig. 4A). Syntaxin, a plasma membrane component of the vesicle docking/ fusion complex (Bennett et al., 1992), is selectively cleaved by BoNt/C (Blasi et al., 1993b). PMA-induced modulation of transport in sense syntaxin oligonucleotide-injected oocytes was eliminated by injection of BoNt/C before assay. In addition, there was a small decrease in uptake in oocytes injected with antisense syntaxin oligonucleotides (see Fig. 5). Neither injection of antisense syntaxin 1a oligonucleotides nor BoNt/C affected nicotineinduced currents in oocytes expressing the $\alpha 7$ acetylcholine receptor (data not shown).

In examining the role of synaptophysin in PMA-induced modulation of the transporter as a function of expression level, we found that the results for GAT1 and rat brain coinjected oocytes treated with synaptophysin antisense oligonucleotides closely resembled the pattern of results for oocytes injected with GAT1 cRNA alone (Fig. $4 B$ ). These results suggest that synaptophysin is at least one component of rat brain mRNA that permits PMAinduced modulation of GAT1 at high expression levels. Charge movement measurements revealed that antisense synaptophysin oligonucleotides blocked the expected PMA-induced increase in functional surface transporter number (Fig. 4C).

To determine whether these trafficking proteins were sufficient to confer PKC-induced modulation of GAT1 at high expression levels, we injected GAT1 cRNA alone or in combination with cRNA encoding human syntaxin 1a (Fig. 4D). Coinjection of syntaxin 1a by itself caused an increase in basal GABA transport $(\sim 30 \%$ above GABA transport in oocytes injected with GAT1 alone), although syntaxin alone conferred no GABA transport. In addition, these GAT1- and syntaxin 1a-coinjected oocytes displayed upregulated transport in response to PMA. This upregulation was also reflected by an increase in surface transporter number and an increase in amounts of protein on the plasma membrane as assessed by immunoblot (data not shown). The specificity of syntaxin 1a action was confirmed by blocking the effect of syntaxin 1a by injection of BoNt/C. Thus, at least one trafficking-associated protein, syntaxin $1 \mathrm{a}$, is itself sufficient to confer regulation at high levels of GAT1 expression.

\section{Docking and fusion proteins are required for modulation of GABA transport}

The effect of synaptophysin and syntaxin 1a antisense oligonucleotides on modulation of GAT1 activity, coupled with the evidence that these proteins are involved in synaptic vesicle trafficking and docking for neurotransmitter release (for review, see Scheller, 1995; Sudhof, 1995), suggested that related proteins may also influence basal expression of GAT1 and/or modulation of GAT1. Recently, several classes of clostridial toxins, long known to be potent inhibitors of neurotransmitter release, have been identified as endoproteases with a specificity for proteins of the docking and fusion complex of synaptic vesicles (for review, see Huttner, 1993). We selected BoNt/A, BoNt/B, and BoNt/C, which proteolytically cleave synaptosomal-associated protein (SNAP)-25, synaptobrevin, and syntaxin, respectively, and assessed their action on basal expression and modulation of GAT1 (in the absence of rat brain mRNA coinjection).

Because we had determined that syntaxin 1a was involved in GAT1 regulation, we used syntaxin 1a inactivation to verify clostridial toxin action in oocytes. Furthermore, homologous BoNt/C substrates exist in non-neuronal cells (Bennett et al., 1993). GAT1-expressing oocytes were microinjected with PMA, BoNt/C, or both, and analyzed for transport activity by uptake assay or for protein localization by subcellular fractionation. BoNt/C significantly reduced basal $\left[{ }^{3} \mathrm{H}\right] \mathrm{GABA}$ transport by $47 \%$ (Student's $t$ test, $p<0.05)$ and similarly eliminated the PMA-induced increase (Fig. 5A, top). The subcellular localization of GAT1 after BoNt/C treatment is shown in Figure $5 A$ (middle and bottom). BoNt/C affected the basal localization of GAT1, reducing GAT1 on the plasma membrane from $21 \%$ of total transporters during the basal state to $4 \%$. Coinjection of BoNt/C with PMA also blocked the dramatic 10-fold shift in transporters translocated to the plasma membrane observed with PMA alone.

SNAP-25 is localized predominantly in presynaptic membranes and is required for synaptic vesicle exocytosis and constitutive vesicle exocytosis in neurons (Sollner et al., 1993); it is selectively cleaved by BoNt/A (Blasi et al., 1993a). To determine whether SNAP-25 affects functional expression of GAT1 and modulation by PMA, oocytes expressing GAT1 were untreated (basal), microinjected with either PMA or BoNt/A, or both. Forty-five minutes after drug injection, a subset of injected oocytes was homogenized for subcellular fractionation of membranes, and a parallel group was assayed for $\left[{ }^{3} \mathrm{H}\right] \mathrm{GABA}$ transport (Fig. $5 B$ ). BoNt/A alone significantly reduced GABA transport to $63 \%$ of basal levels (Student's $t$ test, $p<0.05$ ). BoNt/A coinjected with PMA not only blocked the twofold increase in uptake observed with PMA alone, but again reduced basal transport below that of control levels (Fig. 5B, top). The decrease in uptake activity accompanied a change in the subcellular distribution of transporters located in both plasma membrane and cytoplasmic vesicle fractions. In the basal state, $48 \%$ of total GAT1 protein was found on the plasma membrane, and $52 \%$ was located in cytoplasmic 
A
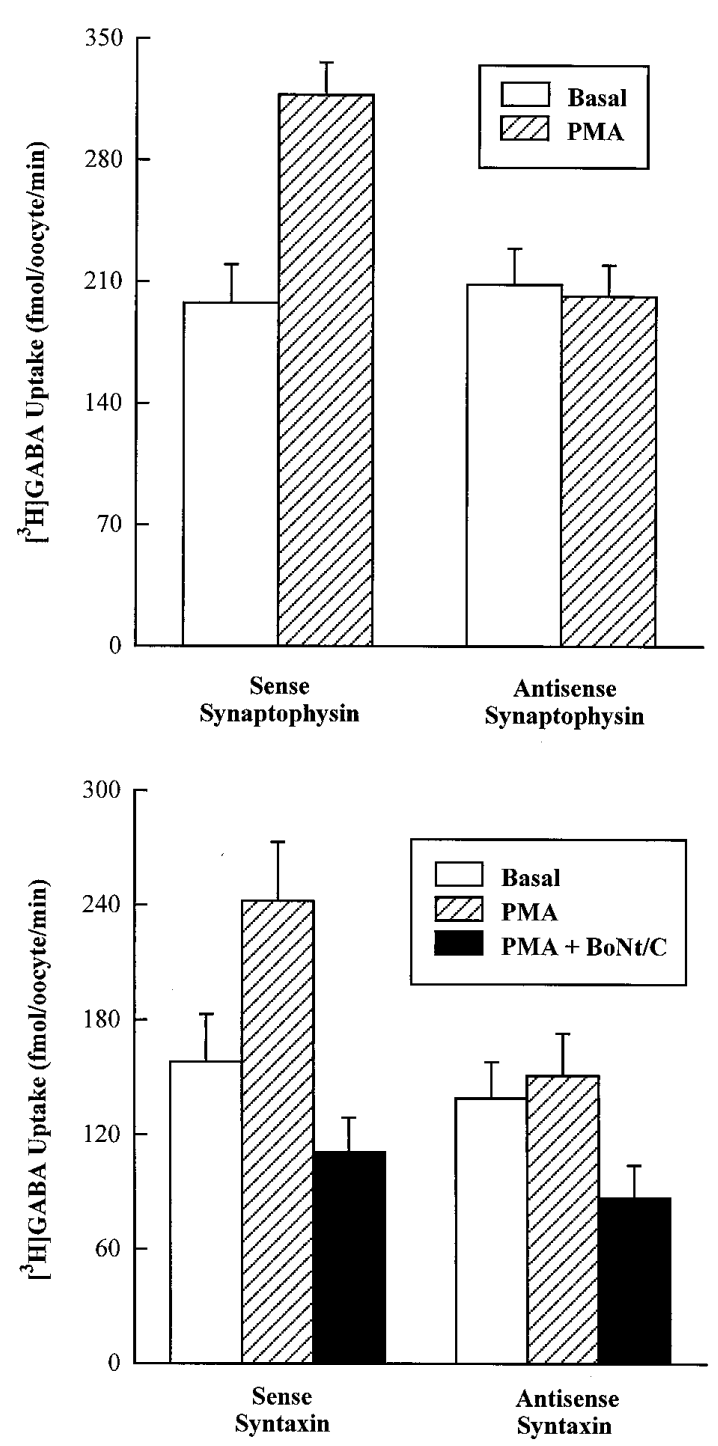

Figure 4. Synaptophysin and syntaxin 1a alter the function and expression of GAT1. A, Coinjection of synaptophysin or syntaxin 1a antisense oligonucleotides in oocytes injected with GAT1 and total rat brain mRNA eliminates PMA-induced modulation. Oocytes were coinjected with $5 \mathrm{ng}$ of GAT1 and $50 \mathrm{ng}$ of rat brain RNA. In addition, oocytes were also injected with $25 \mathrm{ng}$ of either sense (control) or antisense oligonucleotides to synaptophysin or syntaxin 1a at the time of RNA injection, and again $24 \mathrm{hr}$ later. Oocytes were assayed $72 \mathrm{hr}$ after RNA injection. The PMA concentration was $400 \mathrm{~nm}$. For oocytes injected with syntaxin 1a oligonucleotides, a subset of oocytes was injected with $1 \mathrm{ng}$ of BoNt/C. Data are mean \pm SEM. Oocytes (6 oocytes/condition) were assayed for $\left[{ }^{3} \mathrm{H}\right] \mathrm{GABA}$ uptake $15 \mathrm{~min}$ after injection of a control solution (open bars), PMA (hatched bars), or PMA and BoNt/C ( filled bars). Assay time was $15 \mathrm{~min}$. B, Summary data for the effect of sense and antisense synaptophysin oligonucleotide injection. Expression level is quantified as the amount of $\left[{ }^{3} \mathrm{H}\right] \mathrm{GABA}$ uptake in GAT1/rat brain-injected oocytes additionally injected with antisense (filled squares) or sense (open squares) oligonucleotides (abscissa). The change in uptake induced by $400 \mathrm{nM}$ PMA

(ordinate) is plotted as a percentage of vehicle-only injected oocytes. For comparison, the results for oocytes injected with only GAT1 are included (open circles). Each data point represents the mean \pm SEM for three to seven oocytes. Different expression levels were obtained by performing the assay at different times after RNA injection. $C$, PMA-induced changes in oocyte plasma membrane number as assessed by measurement of charge movements. Calculations are described in Materials and Methods. Measurements were made on GAT1/rat brain mRNA-expressing oocytes injected with either sense ( filled circles) or antisense (open circles) oligonucleotides. The data presented are from individual oocytes with comparable initial charge movements and are representative of five oocytes/condition. $D$, Coexpression of syntaxin 1a with GAT1 permits PMA-induced modulation at higher expression levels. Oocytes were assayed $48 \mathrm{hr}$ after RNA injection. Data are mean \pm SEM. Oocytes (5 oocytes/condition) were assayed for [ $\left.{ }^{3} \mathrm{H}\right] \mathrm{GABA}$ uptake $15 \mathrm{~min}$ after injection of a control solution (open bars), 400 nM PMA (hatched bars), or PMA and $1 \mathrm{ng}$ of BoNt/C ( filled bars).

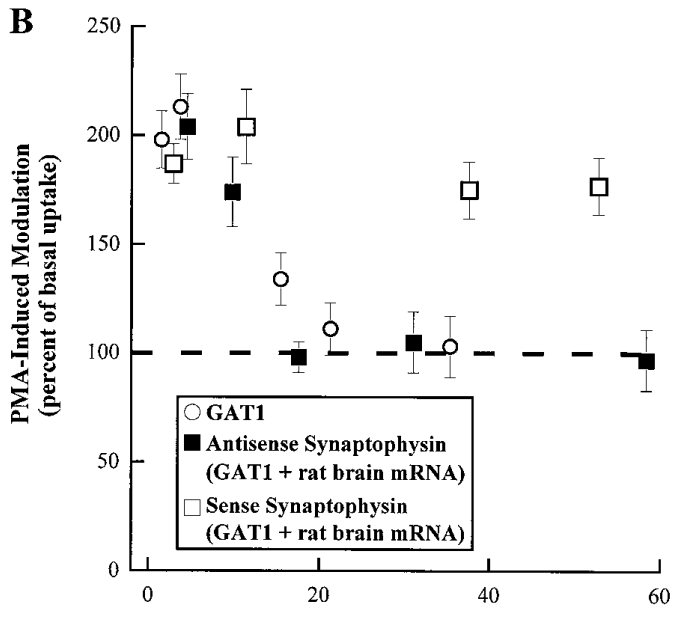

C

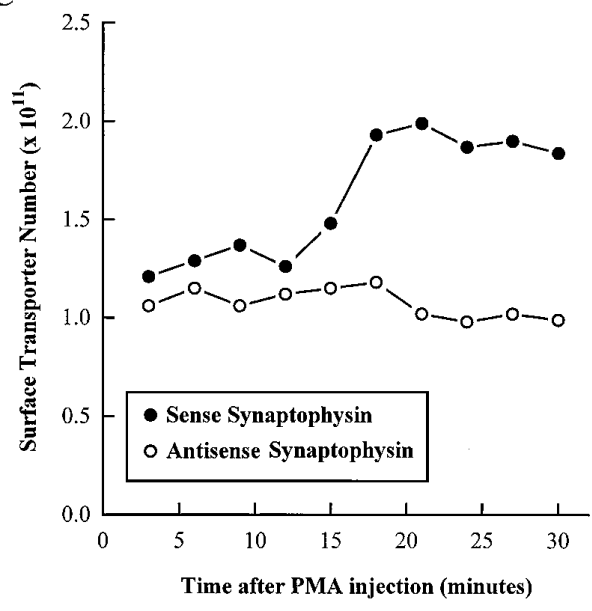

D

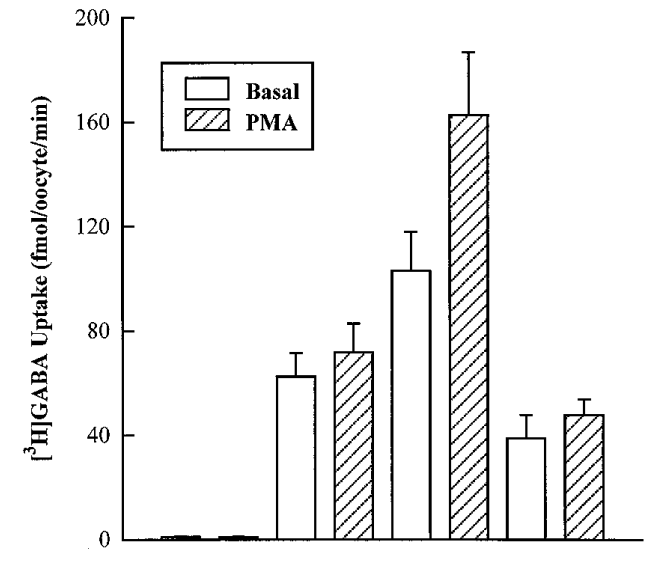

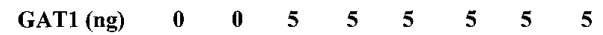
$\begin{array}{lllllllll}\text { yntaxin 1a (ng) } & 0 & \mathbf{5} & 0 & \mathbf{0} & \mathbf{5} & \mathbf{5} & \mathbf{5} & \mathbf{5}\end{array}$ $\begin{array}{lllllll}0 & 0 & 0 & 0 & 0 & 0 & 1\end{array}$ 
A
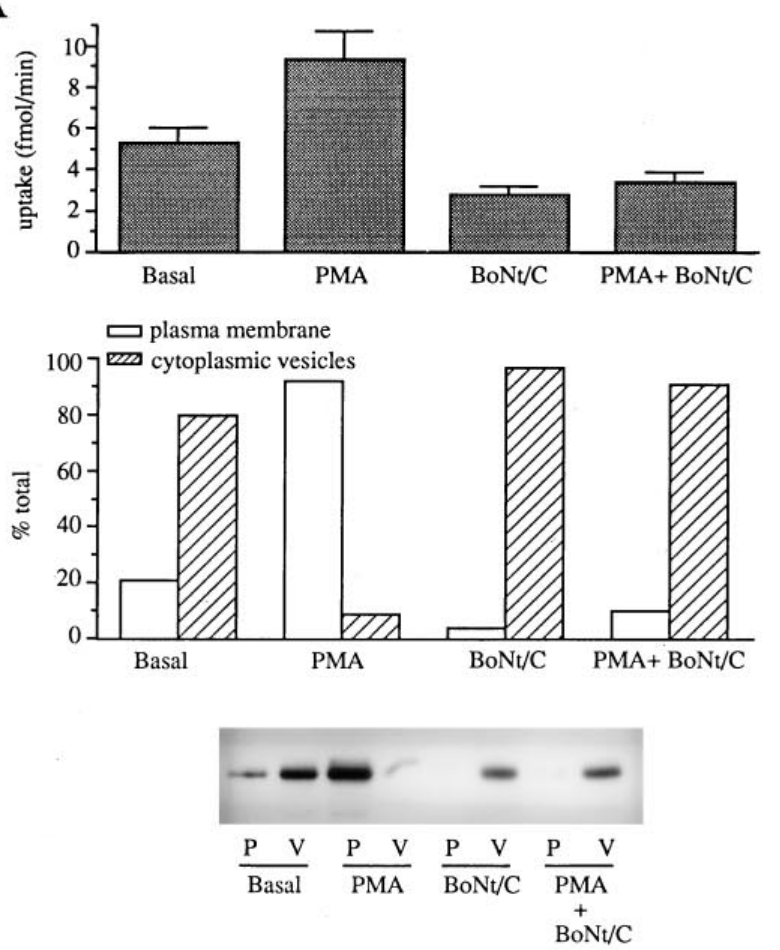

C
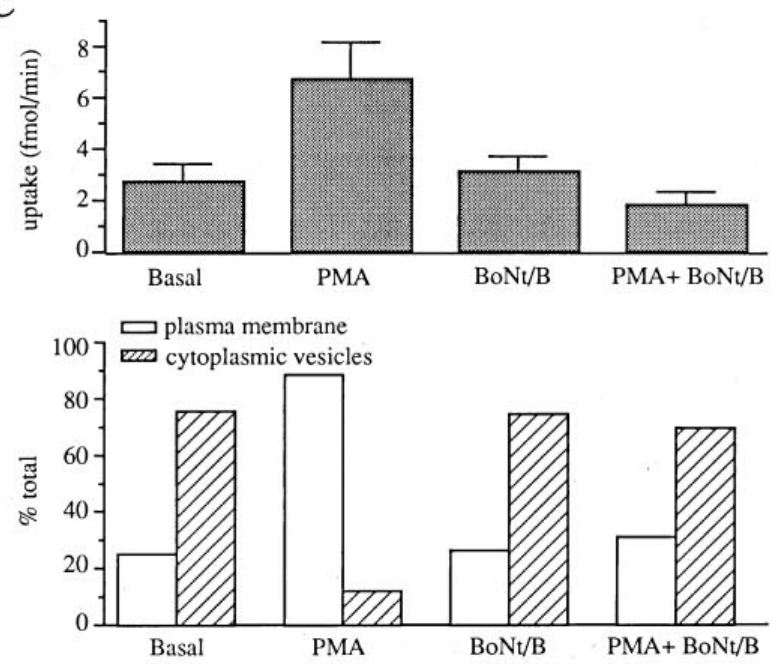

B
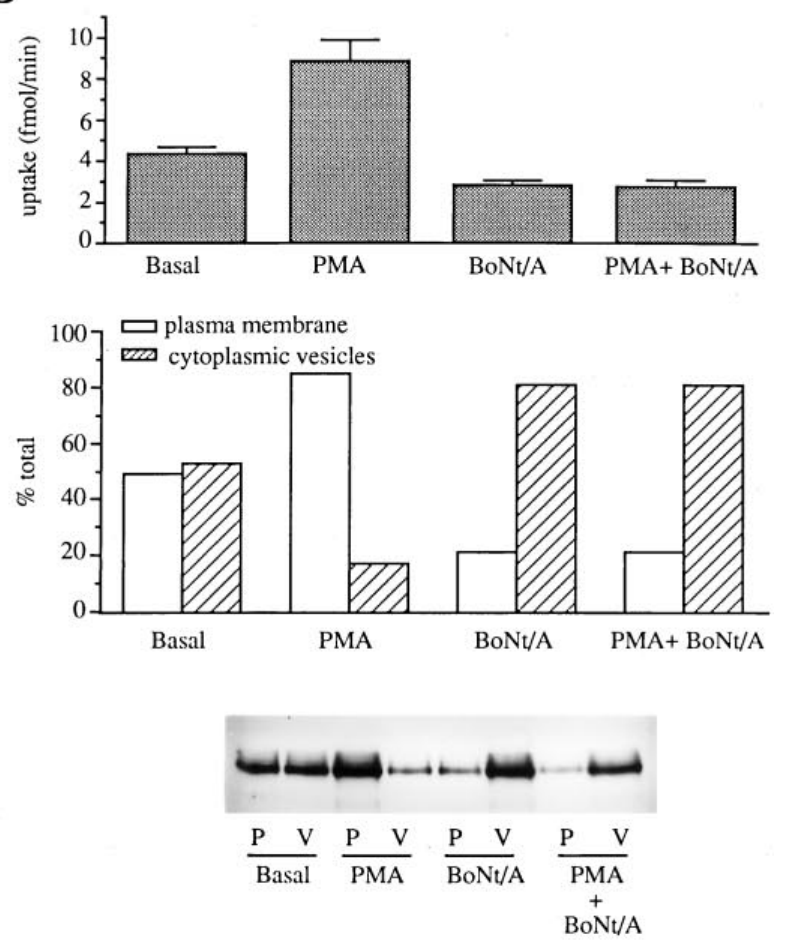

D

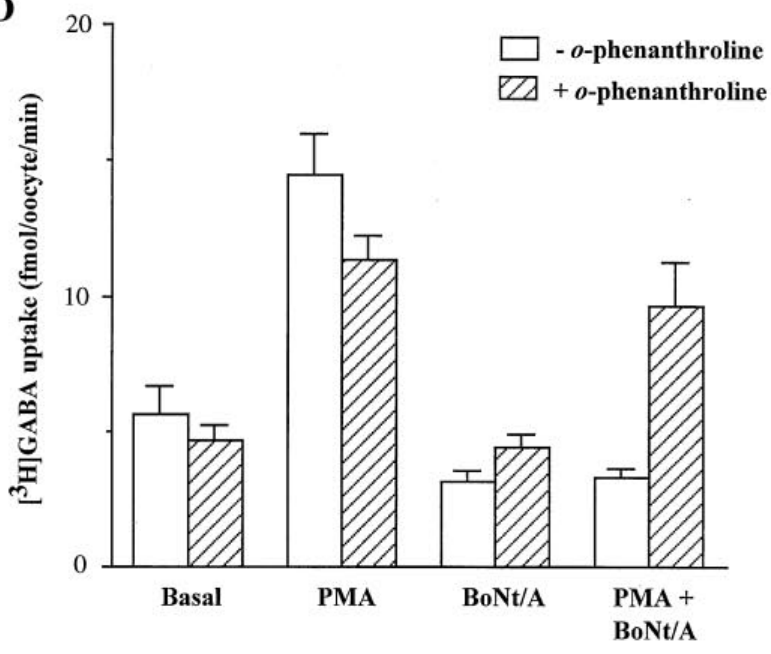

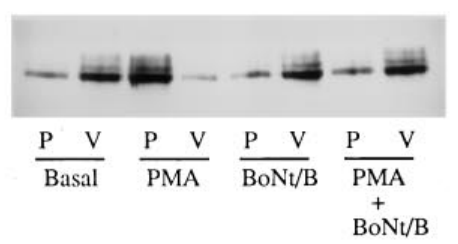

Figure 5. Effect of botulinum toxins on basal GABA transport and on PMA-induced translocation of GAT1. A-C, GAT1-expressing oocytes were untreated (Basal) or injected with $400 \mathrm{nM}$ PMA, botulinum toxin, or both. A subset of these oocytes was assayed 50 min later for $\left[{ }^{3} \mathrm{H}\right] \mathrm{GABA}$ uptake (top). The uptake data represent the mean \pm SEM for five oocytes/condition. The assay time was $15 \mathrm{~min}$. Subcellular fractionation was performed on parallel oocyte samples (25-40 oocytes/sample) and analyzed by equilibrium sedimentation on discontinuous sucrose gradients as described in Materials and Methods. The membrane pellets were resuspended, subjected to SDS-PAGE, and transferred to nitrocellulose, and GAT1 protein present in plasma membrane $(P)$ and cytoplasmic vesicle $(V)$ fractions was visualized by immunoblotting (bottom). Densitometry was performed on the immunoblots, and band densities for the plasma membrane and cytoplasmic vesicle fractions are plotted as a percentage of the total density within each treatment group $(P+V)$ (middle). These results are a representative example from two separate experiments. $A$, Results using BoNt/A (50 ng/oocyte). $B$, Results using BoNt/C (1 ng/oocyte). $C$, Results using BoNt/B (1 ng/oocyte). $D$, Inhibition of the botulinum toxin effects on basal and PMA-induced GABA transport by $o$-phenanthroline. GAT1-expressing oocytes were untreated (Basal) or injected with $400 \mathrm{nM}$ PMA, $50 \mathrm{ng}$ of BoNt/A, or both. One-half of each group were additionally injected with $o$-phenanthroline to a final concentration of $1 \mathrm{~mm}$. 
vesicles. After treatment with BoNt/A, the distribution of transporters shifted to 21 and $79 \%$ located on the plasma membrane and in vesicles, respectively (Fig. $5 B$, middle and bottom). Thus, inhibition of SNAP-25 and of syntaxin-related proteins (each located on the plasma membrane) affects both the basal distribution and the PMA-induced distribution of GAT1.

Synaptobrevin, a component of synaptic vesicles, is believed to function in the secretory pathway (for review, see Buckley, 1994) via interactions with syntaxin, SNAP-25, and the $N$-ethylmaleimide-sensitive fusion protein/soluble NSF attachment protein complex (Sollner et al., 1993); cellubrevin plays a similar role in non-neuronal cells. Both synaptobrevin and cellubrevin are substrates for BoNt/B (Schiavo et al., 1992; McMahon et al., 1993). GAT1-expressing oocytes were treated with PMA, BoNt/B, or both, and assayed for transport activity and subcellular distribution. BoNt/B alone had no significant effect on basal transporter activity (Student's $t$ test, $p<0.20$ ) (Fig. 5C, top). Tenfold and 50-fold higher concentrations of BoNt/B also failed to affect basal transporter activity (data not shown). Consistent with the lack of BoNt/B effects on basal transport, no difference in the subcellular localization of GAT1 in untreated and BoNt/ B-treated oocytes was observed (Fig. 5C, middle and bottom). However, similar to results with BoNt/C and BoNt/A (Fig. 5, $A$ and $B$, respectively), coinjection of BoNt/B with PMA resulted in a block of the 2.5-fold PMA-induced increase (Fig. $5 C$, top). The fractionation results showed that BoNt/B had its effect by preventing the translocation of transporters to the plasma membrane (Fig. 5C, middle and bottom). Therefore, a cellubrevin-related molecule is involved in the PMA-induced translocation of GAT1 but not in the basal level expression of GAT1. This result contrasts with that observed for the plasma membrane-located proteins syntaxin and SNAP-25, which affect the basal level GAT1 expression as well.

To confirm that the actions of the three toxins were attributable to proteolytic cleavage of their substrates rather than to nonspecific effects on the oocytes, we used $o$-phenanthroline, which blocks botulinum toxin effects by chelating the $\mathrm{Zn}^{2+}$ necessary for the proteolytic activity of the toxins. The results for BoNt/A are shown in Figure $5 D$; comparable results were seen for BoNt/B and BoNt/C (data not shown). $\left[{ }^{3} \mathrm{H}\right] \mathrm{GABA}$ uptake was examined in GAT1-expressing oocytes that were PMA-injected, toxininjected, or injected with both. The results obtained were compared with oocytes that were additionally injected with a final concentration of $1 \mathrm{~mm} o$-phenanthroline. As seen previously (Fig. $5 B)$, BoNt/A reduced both the basal uptake of $\left[{ }^{3} \mathrm{H}\right] \mathrm{GABA}$ in GAT1-expressing oocytes and eliminated the PMA-induced increase in uptake activity. In both cases, the addition of $o$-phenanthroline only slightly reduced uptake but significantly reduced the BoNt/A effects. These results suggest that the toxins exert their effects on GABA transport in oocytes via their proteolytic activity.

\section{Removal of a leucine heptad repeat in GAT1 alters GAT1 regulation}

The antisense and toxin data suggested that the regulation of GAT1 distribution and function is associated with proteins involved in trafficking and recycling of proteins in both neural and non-neural cells. In other proteins, including glucose transporters, regions containing repeating leucine motifs play a role in targeting and trafficking (Asano et al., 1992; Matter et al., 1994; Verhey and Birnbaum, 1994; Cool et al., 1995). The primary sequence of GAT1 contains a leucine heptad repeat sequence. Site-directed
A
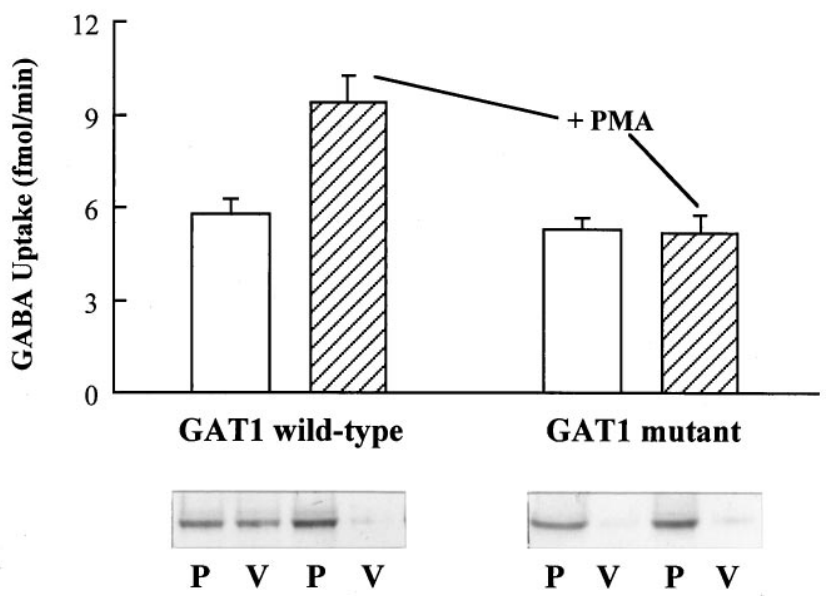

B
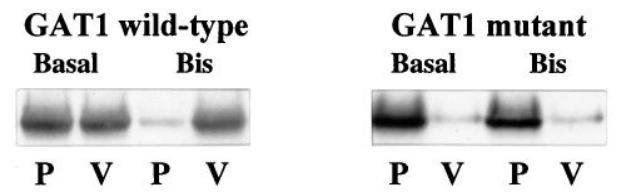

Figure 6. Elimination of a leucine heptad repeat in GAT1 alters transporter regulation. $A$, Oocytes were injected with wild-type GAT1 cRNA or cRNA encoding a mutant GAT1 in which four leucines were changed to alanine (at positions $83,90,97$, and 104). $\left[{ }^{3} \mathrm{H}\right] \mathrm{GABA}$ uptake assays were performed 48 hr later on both basal (open bars) and PMA-treated (hatched bars) oocytes. The PMA concentration was $400 \mathrm{nM}$. The uptake data represent the mean \pm SEM for 15 oocytes/condition. Subcellular fractionation was performed on parallel oocyte samples ( 25 oocytes/sample) and analyzed by equilibrium sedimentation on discontinuous sucrose gradients as described in Materials and Methods. The membrane pellets were resuspended, subjected to SDSPAGE, and transferred to nitrocellulose, and GAT1 protein present in plasma membrane $(P)$ and cytoplasmic vesicle $(V)$ fractions was visualized by immunoblotting. $B$, Immunoblots after subcellular fractionation of oocytes injected with cRNA either for wild-type GAT1 or for the quadruple leucineto-alanine mutant described in $A$. Fifteen minutes before fractionation, oocytes were injected with either $50 \mathrm{nl}$ of vehicle solution (Basal) or $100 \mathrm{nM}$ bisindolylmaleimide (Bis).

mutagenesis (leucine to alanine) at positions 83, 90, 97, and 104 was performed, and the resulting mutant GAT1 cRNA was injected into oocytes (Fig. 6). As expected, in oocytes injected with wild-type GAT1, GABA transport increased in the presence of PMA, and this increase correlated with a movement of GAT1 from intracellular stores to the plasma membrane as assessed by Western blot. However, in oocytes expressing mutant transporters at a comparable expression level, PMA did not induce an increase in GABA transport. These data are consistent with immunoblot data showing that, in the basal state, most of the protein is already at the plasma membrane, and therefore further PMA-induced modulation by translocation is impossible.

We also asked whether the leucine mutations eliminated susceptibility to modulation by decreases in PKC. We performed experiments using the $\mathrm{PKC}$ inhibitor bisindolylmaleimide, which causes a shift in the distribution of wild-type GAT1 from the plasma membrane fraction to the cytoplasmic fraction (Corey et al., 1994). Immunoblot results are shown in Figure $6 B$. The increase in wild-type GAT1 protein found in the cytoplasmic vesicle fraction (and concomitant decrease in GAT1 protein found in the plasma membrane fraction) after bisindolylmaleim- 


\begin{tabular}{|c|c|c|c|c|}
\hline \multicolumn{4}{|c|}{ Position of Leu $\rightarrow$ Ala Mutation } & \multirow{2}{*}{$\begin{array}{l}\text { PMA-induced } \\
{\left[{ }^{3} \mathrm{H}\right] \mathrm{GABA} \text { uptake }} \\
(\% \text { of basal, } \\
\text { mean } \pm \mathrm{SEM})\end{array}$} \\
\hline 83 & 90 & 97 & 104 & \\
\hline Wil & & & & $212 \pm 31$ \\
\hline \multirow[t]{4}{*}{$\mathrm{X}$} & & & & $226 \pm 18$ \\
\hline & $\mathrm{X}$ & & & $198 \pm 25$ \\
\hline & & $\mathrm{X}$ & & $210 \pm 17$ \\
\hline & & & $\mathrm{X}$ & $186 \pm 21$ \\
\hline \multirow[t]{2}{*}{$\mathrm{X}$} & & $X$ & & $191 \pm 27$ \\
\hline & & $\mathrm{X}$ & $\mathrm{X}$ & $173 \pm 14$ \\
\hline X & $X$ & $\mathrm{X}$ & & $90 \pm 21$ \\
\hline $\mathrm{X}$ & & $\mathrm{X}$ & $\mathrm{X}$ & $108 \pm 19$ \\
\hline $\mathrm{X}$ & $\mathrm{X}$ & $\mathrm{X}$ & $\mathrm{X}$ & $95 \pm 14$ \\
\hline
\end{tabular}

ide treatment does not occur for the mutant GAT1 protein. These data suggest that the region of GAT1 containing a leucine heptad repeat motif plays a role both in basal expression of the protein and its susceptibility to regulation by PKC. One intriguing possibility is that this region of GAT1 is required for the entry of the GAT1 protein into a compartment utilizing PKC-regulated trafficking proteins.

Additionally, we examined PMA-induced modulation for a number of mutant GAT1 proteins in which leucines in this region of the protein were mutated individually, in pairs, or in triplicate. These data are summarized in Table 1 for oocytes with low GAT1 expression levels (between 1 and $10 \mathrm{fmol} /$ oocyte/min). No differences in PMA-induced increases in GABA uptake were found when one or two leucines were mutated; removal of any three leucines abolished the PMA-induced modulation.

\section{DISCUSSION}

We have sought to create a model system for examining neurotransmitter transporter regulation that is more favorable than the presynaptic terminal, where the transporter is normally expressed, to permit physiological, biochemical, and cell biological measurements and nucleic acid-based reconstitution of wild-type and mutant transporters. In the oocyte expression system, our data show that the surface level of GAT1 is subject to regulation by mechanisms and molecules, such as clostridial toxin substrates, synaptophysin, syntaxin, and kinases, that regulate many other membrane components of the presynaptic terminal. Additionally, the data show that GAT1 regulation in this model system requires residues homologous to those involved in protein-protein interactions during trafficking of facilitated glucose transporters. These two sets of facts about GAT1 regulation strongly suggest that neurons also have the capacity to regulate GAT1 levels at the presynaptic terminal and that this regulation involves mechanisms and protein domains similar to those that govern the surface level of other transporters in non-neuronal cells. This possible regulation takes on added significance because of the hypothesis that surface density of neurotransmitter transporters is a crucial component in terminating the synaptic event (Mager et al., 1993, 1996; Sarantis et al., 1993; Lester et al., 1996).

\section{Role of trafficking-related proteins}

Synaptophysin, syntaxin, and other substrates for botulinum toxins are associated with specific aspects of basal GAT1 trafficking, PKC-mediated translocation, and functional surface expression. These results suggest a trafficking pathway in oocytes that is analogous to the classical regulated exocytotic pathway of transmitter release, although this suggestion is tentative because trafficking pathways in oocytes have not been well characterized. These data also suggest a close interaction between factors that control secretion and the components regulating neurotransmitter uptake.

The GAT1 transporter expressed at low levels in oocytes is targeted primarily to a PKC-sensitive secretory pathway and stored intracellularly. At high GAT1 expression levels, the ability to modulate transporter function decreases, although the PMAinduced translocation to the plasma membrane fraction still occurs (Corey et al., 1994). The present data show that the addition of rat brain mRNA to oocytes expressing high levels of GAT1 rescues functional modulation, and that secretion-related proteins, such as synaptophysin and syntaxin, mediate this effect. In the most likely interpretation of these data, these proteins are among several components necessary for the translocation of GAT1, and rat brain mRNA complements the endogenous machinery of the oocyte for performing this task. Synaptophysin is a critical component in a neurotransmitter release pathway expressed in oocytes via rat brain RNA (Alder et al., 1992).

Through the use of clostridial toxins that act on these proteins, we have identified components of the vesicle docking/fusion apparatus required for expression and modulation of GAT1 function in oocytes. Both a BoNt/C substrate, presumably homologous to the syntaxins, and a BoNt/A substrate, such as SNAP-25, are necessary for regulation of GAT1 during constitutive recycling as well as for PMA-induced modulation of the transporter. Interestingly, a BoNt/B substrate such as synaptobrevin or cellubrevin is not required for constitutive recycling of the GAT1 transporter, but is necessary for the PKC-regulated translocation of the transporter to the cell surface. This suggests that the requirements for components of the docking/fusion complex may be different for constitutive recycling and regulated expression of plasma membrane proteins. It is also consistent with the findings of Link et al. (1993), in which it is shown that cellubrevin is not required for fusion of vesicles with endosomes in baby hamster kidney cells.

\section{Role of leucine heptad repeat motifs}

Leucine zipper motifs were first identified as regions that mediate DNA-protein binding (Landschulz et al., 1988). More recently, the $\alpha$-helical structures presumed to be formed by leucine heptad repeats have been shown to mediate a number of protein-protein interactions: (1) Heptad repeats occur in regions identified in coiled-coil relationships between SNAP-25 and syntaxin (Chapman et al., 1994). (2) Leucine heptad repeats in transmembrane segments of the hemagglutinin-neuraminidase protein (McGinnes et al., 1993) and gp41 (Bernstein et al., 1995) are responsible for oligomer formation. (3) Mutagenesis of leucine heptad repeats in the heat shock protein HSF2 results in subcellular mislocalization of the protein (Sheldon and Kingston, 1993). In our studies of GAT1, removal of the leucine heptad repeat located in the second putative transmembrane domain does not appear to affect transporter function directly, but still affects transporter localization and modulation. Thus, removal of the leucine heptad repeat (1) causes a redistribution of the transporter such that the majority of the protein is located on the plasma membrane, and (2) eliminates modulation of the transporter by PKC. We speculate that the interaction of this region with other cellular proteins may play a role in the targeting of GAT1 (Ahn et al., 1996) and other transporters to specific regions of the plasma membrane. Members of the glucose transporter family also contain a well con- 
served leucine heptad repeat in the second putative transmembrane domain (White and Weber, 1989), and in studies of chimeric transporters, amino acid residues in this region are partially responsible for targeting of glucose transporter isoforms to intracellular or plasma membrane compartments (Asano et al., 1992). Several other members of the neurotransmitter transporter family display a moderately well conserved leucine heptad motif in transmembrane domain 2 (Giros and Caron, 1993).

\section{Endocytosis versus exocytosis?}

Net membrane trafficking is the sum of endocytotic and exocytotic events. We believe the PMA-induced redistribution of GAT1 results primarily from specific increased exocytosis of GAT1, rather than from decreased endocytosis, for the following reasons. (1) The GAT1 increase occurs despite the general $\sim 35 \%$ endocytotic decrease in membrane area induced by PKC activation. (2) For the $\mathrm{Na}^{+} / \mathrm{K}^{+}$-ATPase, the trafficking of which has been studied in oocytes, basal endocytosis occurs at only $\sim 10 \%$ per hour [Schmalzing et al. (1995), their Fig. 4]. Thus, even if endocytosis were to stop completely, this effect would be too small to account for the present data.

As discussed previously (Corey et al., 1994), the PMA-induced translocation of GAT1 could be explained either by increasing the rate of constitutive exocytosis or by stimulating secretion from a stored pool of transporters in a regulated pathway. Evidence for the former hypothesis comes from studies in which PMA affects trafficking rates (Cardone et al., 1994). However, our data suggest a contribution from a regulated pathway for the following reasons. (1) The involvement of synaptophysin and of botulinum toxin substrates points to the role of proteins generally thought to participate in regulated exocytotic pathways. (2) Regulation by calcium (our unpublished observations), a defining characteristic of regulated secretion pathways, occurs in GAT1 translocation. Addressing the relative contributions of exocytotic and endocytotic pathways in transporter regulation and delineating the specific components in oocyte trafficking pathways are goals of future experiments.

The demonstration that a neurotransmitter transporter heterologously expressed in oocytes is targeted to a trafficking pathway involving elements in common with the well characterized pathway for neurotransmitter release underscores the concept that the molecular machinery for secretion is conserved from yeast to neurons (Bennett and Scheller, 1993). Scheuner et al. (1992) demonstrated that the constituents of chromaffin granule membranes are sufficient to reconstitute exocytosis when injected into Xenopus oocytes and proposed that the ability to substitute mammalian and amphibian secretory pathway components suggests substantial biochemical conservation of the exocytotic pathway. Homologs for both synaptobrevin and syntaxin have been found in non-neuronal tissue (Bennett et al., 1993; McMahon et al., 1993), including glucose transporter-containing vesicles of rat adipocytes (Cain et al., 1992). These findings suggest a general mechanism for membrane trafficking shared by all cells. Not only are component proteins conserved, but the actual pathway of secretion may have evolved from a more basic mechanism of membrane repair. Steinhardt et al. (1994) demonstrated that after injury to the cell membrane of sea urchin embryos and fibroblasts, resealing of the membrane occurs by a mechanism involving vesicle delivery, docking, and fusion similar to the exocytosis of neurotransmitters.

Modulation of neurotransmitter uptake by redistribution of transporters from cytoplasmic stores to the plasma membrane has important implications for the proposed function of these transporters in terminating and spatially localizing synaptic transmission. Our data show that the density of GABA transporters at the plasma membrane can be regulated by a mechanism involving second-messenger cascades that occur in neurons, and that domains that control targeting in other transporter families do so for GAT1 as well. In addition, we show that modulation of the GABA transporter expressed in oocytes occurs via vesicular trafficking and includes components similar to those found in secretion. This system will also be useful for examining exocytotic events in vesicle docking and fusion, and it may provide insight into the participation of transporters in this process.

\section{REFERENCES}

Ahn J, Mundigl O, Muth TR, Rudnick G, Caplan MJ (1996) Polarized expression of GABA transporters in Madin-Darby canine kidney cells and cultured hippocampal neurons. J Biol Chem 271:6917-6924.

Alder J, Lu B, Valtorta F, Greengard P, Poo M (1992) Calciumdependent transmitter secretion reconstituted in Xenopus oocytes: requirement for synaptophysin. Science 257:657-661.

Asano T, Takata K, Katagiri H, Tsukuda K, Lin J-L, Ishihara H, Inukai K, Hirano H, Yazaki Y, Oka Y (1992) Domains responsible for the differential targeting of glucose transporter isoforms. J Biol Chem 267:19636-19641.

Bennett MK, Scheller RH (1993) The molecular machinery for secretion is conserved from yeast to neurons. Proc Natl Acad Sci USA 90:2559-2563.

Bennett MK, Calakos N, Scheller RH (1992) Syntaxin: a synaptic protein implicated in docking of synaptic vesicles at presynaptic active zones. Science 257:255-259.

Bennett MK, Garcia-Arraras JE, Elferink LA, Peterson K, Fleming AM, Hazuka CD, Scheller RH (1993) The syntaxin family of vesicular transport receptors. Cell 74:863-873.

Bernstein HB, Tucker SP, Kar SR, McPherson SA, McPherson DT, Dubay JW, Lebowitz J, Compans RW, Hunter E (1995) Oligomerization of the hydrophobic heptad repeat of gp41. J Virol 69:2745-2750.

Blasi J, Chapman ER, Link E, Binz T, Yamasaki S, De Camilli P, Sudhof TC, Niemann H, Jahn R (1993a) Botulinum neurotoxin A selectively cleaves the synaptic protein SNAP-25. Nature 365:160-163.

Blasi J, Chapman ER, Yamasaki S, Binz T, Niemann H (1993b) Botulinum neurotoxin $\mathrm{C} 1$ blocks neurotransmitter release by means of cleaving HPC-1/syntaxin. EMBO J 12:4821-4828.

Bourinet E, Fournier F, Lory P, Charnet P, Nargeot J (1992) Protein kinase $\mathrm{C}$ regulation of cardiac calcium channels expressed in Xenopus oocytes. Pflügers Arch 421:247-255.

Buckley KM (1994) Molecular analysis of a secretory organelle: structure and function of synaptic vesicle-specific proteins. J Membr Biol 139:75-80.

Cain CC, Trimble WS, Lienhard GE (1992) Members of the VAMP family of synaptic vesicle proteins are components of glucose transporter-containing vesicles from rat adipocytes. J Biol Chem 267:11681-11684.

Cardone MH, Smith BL, Song WX, Mochly-Rosen D, Mostov KE (1994) Phorbol myristate acetate-mediated stimulation of transcytosis and apical recycling in MDCK cells. J Cell Biol 124:717-727.

Casado M, Bendahan A, Zafra F, Danbolt NC, Aragon C, Gimenez C, Kanner BI (1993) Phosphorylation and modulation of brain glutamate transporters by protein kinase C. J Biol Chem 268:27313-27317.

Chapman ER, An S, Barton N, Jahn R (1994) SNAP-25, a t-snare which binds to both syntaxin and synaptobrevin via domains that may form coiled coils. J Biol Chem 269:27427-27432.

Cool DR, Fenger M, Snell CR, Loh YP (1995) Identification of the sorting signal motif within proopiomelanocortin for the regulated secretory pathway. J Biol Chem 270:8723-8729.

Corey JL, Davidson N, Lester HA, Brecha N, Quick MW (1994) Protein kinase $\mathrm{C}$ modulates the activity of a cloned GABA transporter expressed in Xenopus oocytes via regulated subcellular redistribution of the transporter. J Biol Chem 269:14759-14767.

Cushman SW, Wardzala LJ (1980) Potential mechanism of insulin action on glucose transport in the isolated rat adipose cell. Apparent translocation of intracellular transport systems to the plasma membrane. J Biol Chem 255:4758-4762. 
Delézay O, Baghdiguian S, Fantini J (1995) The development of $\mathrm{Na}^{+}$dependent glucose transport during differentiation of an intestinal epithelial cell clone is regulated by protein kinase C. J Biol Chem 270:12536-12541.

Dierks P, van Ooyen A, Mantei N, Weissmann C (1981) DNA sequences preceding the rabbit beta-globin gene are required for formation in mouse L cells of beta-globin RNA with the correct $5^{\prime}$ terminus. Proc Natl Acad Sci USA 78:1411-1415.

Giros B, Caron MG (1993) Molecular characterization of the dopamine transporter. Trends Pharmacol Sci 14:43-49.

Guastella J, Nelson N, Nelson H, Czyzyk L, Keynan S, Miedel MC, Davidson N, Lester HA, Kanner BI (1990) Cloning and expression of a rat brain GABA transporter. Science 249:1303-1306.

Huttner WB (1993) Cell biology. Snappy exocytoxins. Nature 365:104-105.

Iversen LL (1975) Uptake process of biogenic amines. In: Handbook of psychopharmacology, Vol 3 (Iversen SJ, Snyder SH, eds), pp 381-442. New York: Plenum.

Laemmli UK (1970) Cleavage of structural proteins during the assembly of the head of bacteriophage T4. Nature 227:680-685.

Landschulz WH, Johnson PF, McKnight SL (1988) The leucine zipper: a hypothetical structure common to a new class of DNA binding proteins. Science 240:1759-1764.

Leonard JP, Nargeot J, Snutch T, Davidson N, Lester HA (1987) Ca channels induced in Xenopus oocytes by rat brain mRNA. J Neurosci 7:875-881.

Lester HA, Mager S, Quick MW, Corey JL (1994) Permeation properties of neurotransmitter transporters. Annu Rev Pharmacol Toxicol 34:219-250.

Lester HA, Mager S, Cao Y (1996) Listening to neurotransmitter transporters. Neuron 17:807-810.

Link E, McMahon H, Von Mollard GF, Yamasaki S (1993) Cleavage of cellubrevin by tetanus toxin does not affect fusion of early endosomes. J Biol Chem 268:18423-18426.

Mager S, Corey-Naeve J, Quick M, Labarca C, Davidson N, Lester HA (1993) Steady states, charge movements, and rates for a cloned GABA transporter expressed in Xenopus oocytes. Neuron 10:177-188.

Mager S, Kleinberger-Doron N, Keshet GI, Davidson N, Kanner BI, Lester HA (1996) Ion binding and permeation at the GABA transporter GAT1. J Neurosci 16:5405-5414.

Matter K, Yamamato EM, Mellman I (1994) Structural requirements and sequence motifs for polarized sorting and endocytosis of LDL and FC receptor in MDCK cells. J Cell Biol 126:991-1004.

McGinnes L, Sergel T, Morrison T (1993) Mutations in the transmembrane domain of the HN protein of Newcastle disease virus affect the structure and activity of the protein. Virology 196:101-110.

McMahon HT, Ushkaryov YA, Edelmann L, Link E, Binz T, Niemann H (1993) Cellubrevin is a ubiquitous tetanus-toxin substrate homologous to a putative synaptic vesicle fusion protein. Nature 364:346-349.

Osawa I, Saito N, Koga T, Tanaka C (1994) Phorbol ester-induced inhibition of GABA uptake by synaptosomes and by Xenopus oocytes expressing GABA transporter (GAT1). Neurosci Res 19:287-293.

Qian Y, Galli A, Ramamoorthy S, Risso S, DeFelice LJ, Blakely RD
(1997) Protein kinase C activation regulates human serotonin transporters in HEK-293 cells via altered cell surface expression. J Neurosci 17:45-57.

Quick MW, Lester HA (1994) Methods for expression of excitability proteins in Xenopus oocytes. In: Methods in neuroscience: ion channels of excitable cells (Conn PM, ed), pp 261-279. San Diego: Academic.

Sarantis M, Ballerini L, Miller B, Silver RA, Edwards M, Attwell D (1993) Glutamate uptake from the synaptic cleft does not shape the decay of the non-NMDA component of the synaptic current. Neuron 11:541-549.

Sardet C, Counillon L, Franchi A, Pouyssegur J (1990) Growth factors induce phosphorylation of the $\mathrm{Na}^{+} / \mathrm{H}^{+}$antiporter, glycoprotein of 110 $\mathrm{kDa}$. Science 247:723-726.

Sato K, Betz H, Schloss P (1995) The recombinant GABA transporter GAT1 is downregulated upon activation of protein kinase C. FEBS Lett 375:99-102.

Scheller RH (1995) Membrane trafficking in the presynaptic nerve terminal. Neuron 14:893-897.

Scheuner D, Logsdon CD, Holz RW (1992) Bovine chromaffin granule membranes undergo $\mathrm{Ca}(2+)$-regulated exocytosis in frog oocytes. J Cell Biol 116:359-365.

Schiavo G, Benfenati F, Poulain B, Rosetto O, Polverino de Laureto P, DasGupta B, Montecucco C (1992) Tetanus and botulinum-B neurotoxins block neurotransmitter release by proteolytic cleavage of synaptobrevin. Nature 359:832-835.

Schmalzing G, Richter HP, Hansen A, Schwarz W, Just I, Aktories K (1995) Involvement of the GTP binding protein Rho in constitutive endocytosis in Xenopus laevis oocytes. J Cell Biol 130:1319-1332.

Sheldon LA, Kingston RE (1993) Hydrophobic coiled coil domains regulate the subcellular localization of human heat shock factor 2. Genes Dev 7:1549-1558.

Sollner T, Whiteheart SW, Brunner M, Erdjument-Bromage H, Geromanos S, Tempst P, Rothman JE (1993) SNAP receptors implicated in vesicle targeting and fusion. Nature 362:318-324.

Steinhardt RA, Bi G, Alderton JM (1994) Cell membrane resealing by a vesicular mechanism similar to neurotransmitter release. Science 263:390-393.

Sudhof TC (1995) The synaptic vesicle cycle: a cascade of protein-protein interactions. Nature 375:645-653.

Sudhof TC, Lottspeich F, Greengard P, Mehl E, Jahn R (1987) The cDNA and derived amino acid sequences for rat and human synaptophysin. Nucleic Acids Res 15:9607.

Suzuki K, Kono T (1980) Evidence that insulin causes translocation of glucose transport activity to the plasma membrane from an intracellular storage site. Proc Natl Acad Sci USA 77:2542-2545.

Verhey KJ, Birnbaum MJ (1994) A leu-leu sequence is essential for COOH-terminal targeting signal of GLUT4 glucose transporter in fibroblasts. J Biol Chem 269:2353-2356.

White MK, Weber MJ (1989) Leucine-zipper motif update. Nature 340:103-104.

Yunger LM, Fowler PJ, Zarevics P, Setler PE (1984) Novel inhibitors of gamma-aminobutyric acid (GABA) uptake: anticonvulsant actions in rats and mice. J Pharmacol Exp Ther 228:109-115. 